\title{
Stress-induced cleavage of Myc promotes cancer cell survival
}

\author{
Maralice Conacci-Sorrell, ${ }_{1,3}$ Celine Ngouenet, ${ }^{1}$ Sarah Anderson, ${ }^{1}$ Thomas Brabletz, ${ }^{2}$ \\ and Robert N. Eisenman ${ }^{1,3}$ \\ ${ }^{1}$ Division of Basic Sciences, Fred Hutchinson Cancer Research Center, Seattle, Washington 98109, USA; ${ }^{2}$ Department of Visceral \\ Surgery, Comprehensive Cancer Center, University of Freiburg, 79095 Freiburg, Germany
}

\begin{abstract}
Evasion of apoptosis is critical in Myc-induced tumor progression. Here we report that cancer cells evade death under stress by activating calpain-mediated proteolysis of Myc. This generates Myc-nick, a cytoplasmic, transcriptionally inactive cleavage product of Myc. We found conversion of Myc into Myc-nick in cell lines and tissues derived from multiple cancers. In colon cancer, the production of Myc-nick is enhanced under stress conditions such as hypoxia and nutrient deprivation. Under these conditions, ectopic expression of Myc-nick promotes anchorage-independent growth and cell survival at least in part by promoting autophagy. Myc-nick also delays colon cancer cell death after treatment with chemotherapeutic drugs such as etoposide, cisplatin, and imatinib. Furthermore, colon cancer cells expressing a cleavage-resistant form of Myc undergo extensive apoptosis but are rescued by overexpression of Myc-nick. We also found that ectopic expression of Myc-nick results in the induction of the actin-bundling protein fascin, formation of filopodia, and increased cell motility-all mediators of tumor metastasis. Myc-nick-induced survival, autophagy, and motility require Myc box II (MBII), a region of Myc-nick that recruits acetyltransferases that in turn modify cytoplasmic proteins, including $\alpha$-tubulin and ATG3. Our results suggest that Myc-nick-induced survival and motility contribute to colon cancer progression and metastasis.
\end{abstract}

[Keywords: Myc; Myc-nick; hypoxia; autophagy; motility; fascin]

Supplemental material is available for this article.

Received September 30, 2013; revised version accepted February 27, 2014.

The Myc family (c-Myc, N-Myc, and L-Myc) of basic region helix-loop-helix zipper (bHLHLZ) transcription factors promotes cell growth and proliferation and is aberrantly activated in human tumors (Dang 2012). Tumorassociated activation of Myc occurs through multiple mechanisms, leading to up-regulation of Myc levels or activity in order to drive oncogenic transformation (Dang 2012). For example, aberrant activation of the Wnt signaling pathway found in colon carcinomas promotes the transcriptional up-regulation of Myc (He et al. 1998), which is essential for colon cancer initiation (Sansom et al. 2007).

A major biological function of Myc is to increase biomass accumulation, thereby providing the molecular precursors required for the accelerated growth of cancer cells. This increase in biomass is largely supported by Myc's ability to promote ribosomal biogenesis and protein synthesis and to augment the uptake and metabolism of carbon sources such as glucose and glutamine (Shim et al. 1997; Kim et al. 2004; Ji et al. 2011). Further-

${ }^{3}$ Corresponding author

E-mail eisenman@fhcrc.org

Article is online at http://www.genesdev.org/cgi/doi/10.1101/gad.231894.113. more, Myc reprograms metabolism by directly controlling mitochondrial biogenesis and activity, driving the utilization of anabolic pathways that yield both an overall high level of ATP and recyclable metabolites. Therefore, cells with hyperactivated Myc possess a competitive growth and proliferative advantage over normal cells. However, deregulated expression of Myc alone is usually insufficient to convert most normal cell types into tumor cells. This is because Myc, in addition to its growthpromoting activities, also induces apoptosis, which is considered to be an intrinsic mechanism to suppress oncogenic transformation (Evan et al. 1992; Shortt and Johnstone 2012). Secondary genetic changes that bypass the cell death pathway (for example, in p53 and Arf) are required in order for deregulated Myc to transform normal cells (Wagner et al. 1994; Hermeking et al. 1995; Zindy et al. 1998). Importantly, cancer cells expressing high levels of Myc are more sensitive to glucose and

(C) 2014 Conacci-Sorrell et al. This article is distributed exclusively by Cold Spring Harbor Laboratory Press for the first six months after the fullissue publication date (see http://genesdev.cshlp.org/site/misc/terms. xhtml). After six months, it is available under a Creative Commons License (Attribution-NonCommercial 4.0 International), as described at http://creativecommons.org/licenses/by-nc/4.0/. 
glutamine deprivation than normal cells (for review, see Dang 2013). This reliance on carbon sources becomes crucial as tumor size increases and oxygen and nutrients become limiting due to insufficient vascularization. Under these conditions, there is selective pressure for transformed cells to develop the ability to survive stressinduced cell death. For example, to prevent Myc-induced cell death under hypoxia, Myc function is directly inhibited by Hif2 (Keith et al. 2011), and Myc levels are down-regulated through proteasomal degradation (Li et al. 2009; Wong et al. 2013).

Myc proteins function predominantly as transcriptional regulators, exerting most of their biological functions by directly activating the transcription of genes that are primarily involved in the control of cell growth, proliferation, ribosomal biogenesis, and metabolism (Eilers and Eisenman 2008). To bind DNA, Myc forms heterodimers with its partner, Max, and recruits chromatin-modifying complexes to target gene promoters (Orian et al. 2003; Dang 2011). For example, Myc recruits histone acetyltransferase (HAT) complexes such as TRAPPGCN5, Tip60, and Tip48 (McMahon et al. 2000) to promote histone acetylation and facilitate transcription (Guccione et al. 2006; Knoepfler et al. 2006). Moreover, recruitment of the $\mathrm{P}-\mathrm{TEFb}$ transcriptional anti-pausing complex is linked to Myc's function as a widespread regulator of transcription elongation. This is thought to lead to increased expression of all transcriptionally activated or poised genes within a given cell (Rahl et al. 2010; Nie et al. 2012).

Recently, we detected a transcriptionally inactive form of Myc that is localized in the cytoplasm. This N-terminal truncation of Myc, named Myc-nick, performs an active role in the cytoplasm that is independent of Myc's transcriptional activity (Conacci-Sorrell et al. 2010). Full-length Myc is converted into Myc-nick by calcium-dependent cytosolic proteases that are members of the calpain family. Unlike proteasomal degradation leading to total protein destruction, calpain-mediated proteolysis cleaves Myc to generate Myc-nick, which comprises the N-terminal region of Myc from residues 1-298 (Fig. 1A). Myc-nick binds microtubules and recruits acetyltransferases to promote $\alpha$-tubulin acetylation and microtubule stabilization. In addition, Myc-nick was found to accelerate the differentiation of committed myoblasts /Conacci-Sorrell et al. 2010). While normal regulation of calpain activity is essential for embryonic development and targets Myc and other proteins in most normal tissues (ConacciSorrell and Eisenman 2011), aberrant calpain levels and activity have been correlated with tumor development and metastasis (Storr et al. 2011). Consistent with the ubiquitous activity of calpains in normal and tumor cells, we found endogenously expressed Myc-nick in the cytoplasm of a large number of cell types. Among these are normal cells such as fibroblasts and primary cells and several transformed cell lines /Conacci-Sorrell et al. 2010). Furthermore, several immunohistochemical studies have described a cytoplasmic signal for Myc in tumors of diverse origins (Bai et al. 1994; Pietilainen et al. 1995; Calcagno et al. 2009; Ruzinova et al. 2010).
Because Myc-nick is the major form of Myc present in the cytoplasm, it is likely that the cytoplasmic signal for Myc in these tumors corresponds to Myc-nick. The above findings prompted us to investigate the presence and activity of Myc-nick in tumor progression. Here we report that Myc-nick is expressed in a wide range of tumors and show that it is generated in response to metabolic and cytotoxic stress. Under these conditions, Myc-nick augments tumor cell survival by promoting autophagy and, moreover, augments cancer cell motility by inducing fascin expression and filopodia formation.

\section{Results}

Myc-nick is expressed in tumor cell lines and tissues

In order to determine whether Myc-nick functions in tumorigenesis, we extended our previous observations and analyzed the forms of Myc (Myc and Myc-nick) expressed in cancer cell lines and tissues derived from different origins. We examined Myc-nick levels by Western blot using a mixture of two monoclonal pan-Myc antibodies, 143 and 274 (Fig. 1A), which recognize the $\mathrm{N}$ terminus of Myc proteins and therefore are capable of binding both full-length Myc and Myc-nick (ConacciSorrell et al. 2010). We determined the levels of expression of Myc variants in lymphoma, thymic tumors, prostate cancer, neuroblastomas, medulloblastomas, and colon carcinoma (Fig. 1).

Using the $\mathrm{E} \mu$-myc mouse model of Myc-driven lymphoma (Adams and Cory 1985), we found that Myc-nick is present in precancerous bone marrow-derived pre-B cells along with full-length Myc (Fig. 1B). Moreover, both Myc and Myc-nick are highly expressed in sporadic thymic tumors (Fig. 1C). Prostate cancer xenografts derived from human cells propagated in mice also displayed high levels of Myc-nick (Fig. 1D). The multiband pattern observed in prostate cancer samples is probably due to post-translational modifications of both full-length Мус and Myc-nick proteins.

We also analyzed neuroblastoma cell lines containing amplified (IMR32 and SKNBE) or nonamplified (SKNAS) MycN. The cleaved form of MycN was abundant only in the MycN amplified lines (Fig. 1E), consistent with our previous observation that $\mathrm{MycN}$ can also be converted into Myc-nick (Conacci-Sorrell et al. 2010). For medulloblastomas, we analyzed tumors derived from the constitutively activated SMO mouse model of hedgehog-induced medulloblastomas, where $\mathrm{MycN}$ plays an essential role in tumorigenesis (Hatton et al. 2006). We found that Myc-nick is present in a subset of these medulloblastomas (Fig. 1F).

Finally, we assessed the expression of Myc in a collection of human colon cancer cell lines and found that both Myc and Myc-nick are highly expressed in all of these lines (Fig. 1G), as compared with the normal intestinal epithelial cell line FHS74, which expresses low levels of Myc (Fig. 1H). Moreover, we found both Myc and Myc-nick to be highly expressed in crypts isolated from small 

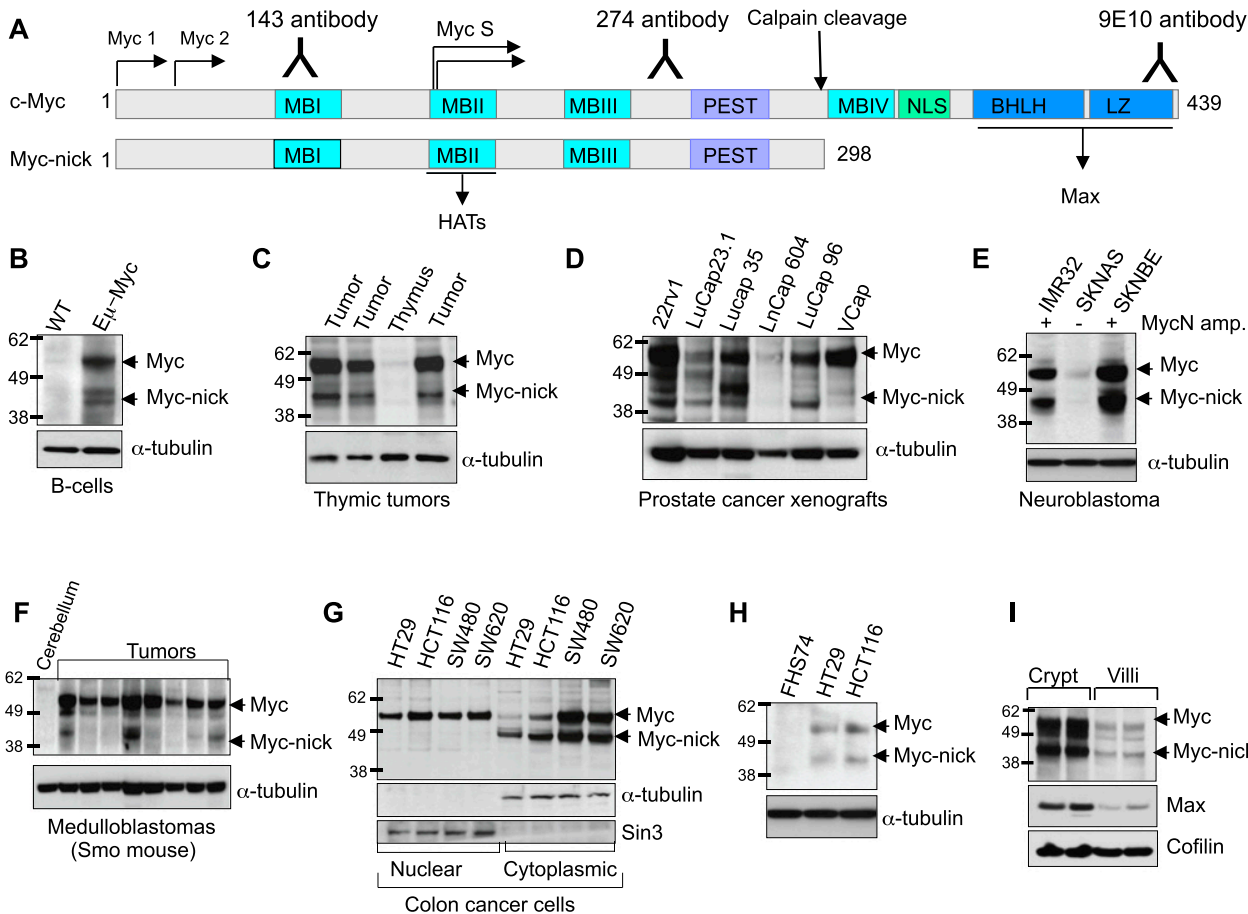

I

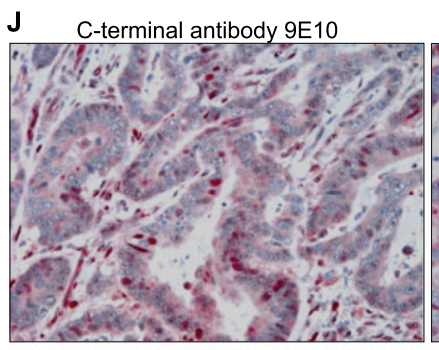

N-terminal antibody 274
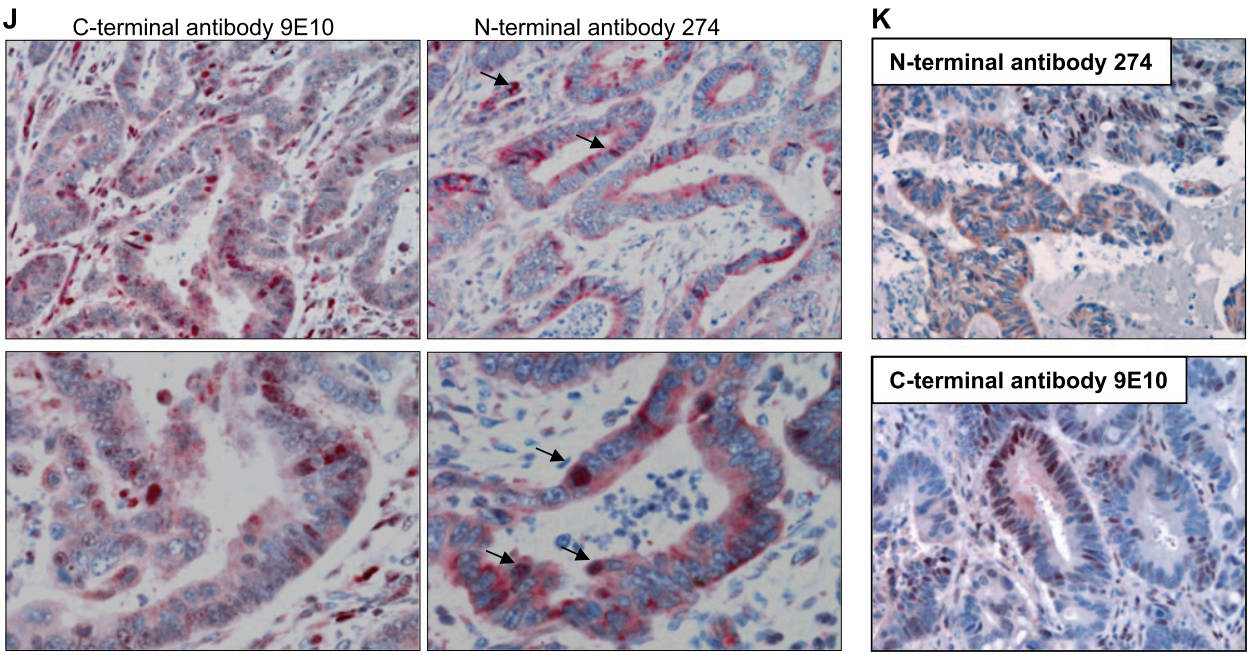

Figure 1. Myc-nick is expressed in tumor cell lines and tissues. (A) Schematic representation of Myc and Myc-nick. (MB) Myc box $(\mathrm{I}-\mathrm{IV}) ;(\mathrm{NLS})$ nuclear localization sequence. $(B-F)$ Total cell lysates were prepared from snap-frozen tissues and processed for Western blot. (B) Western blots of total protein extracts derived from wild-type (WT) or E $\mu$-myc B cells prior to tumor development. (C) Western blots of total protein extracts derived from mouse thymic tumors and normal thymus. $(D)$ Western blots of protein extracts derived from prostate cancer xenografts. $(E)$. Western blot of two neuroblastoma cell lines with amplified MycN (IMR32 and SKNBE) and one line without amplification (SKNAS). (F) Total protein extracts of medulloblastomas derived from the Smo mouse model compared with a normal cerebellum. (G) Colon cancer cell lines cultured for $4 \mathrm{~d}$ after reaching confluency were fractionated into nuclear and cytoplasmic fractions. $(H)$ Colon cancer cell lines express high levels of Myc when compared with normal intestinal epithelial cells. (I) Myc-nick is expressed in normal mouse intestinal crypts and villi. Crypts and villi independently isolated from small intestines from two mice were processed for Western blot. ( $/$ ) Antibodies against the $\mathrm{N}$ terminus of Myc detect Myc in the nucleus and cytoplasm of human colorectal cancer tissues. Sections of the same colorectal cancer biopsies were subjected to immunohistochemistry using an antibody against the $\mathrm{C}$ terminus of Myc (9E10) and an antibody against the $\mathrm{N}$ terminus of Myc (274). The bottom panels show sequential sections of the same tumor. Arrows point to nuclear staining. $(K)$ Additional colorectal tumor biopsies display similar patterns of staining. Note that the 9E10 antibody stains predominantly nuclear Myc, while 274 stains both nuclear and cytoplasmic compartments (see also Supplemental Table S1).

intestines of normal mice (Fig. 1I). Crypts are regions where colorectal cancer is initiated and cancer stem cells reside (Dalerba et al. 2007; Ricci-Vitiani et al. 2007).
Overall, we found Myc-nick protein to be present in the majority of the tumor samples analyzed. Myc-nick is less abundant than full-length Myc in proliferating cells but is usually the predominant form of Myc in nonproliferative 
cells that are cultured at high density (Fig. 2F; Supplemental Fig. S2A,B; Conacci-Sorrell et al. 2010). In general, tumors with high levels of Myc also exhibited high levels of Myc-nick; however, we observed some exceptions to this correlation (e.g., Fig. 1D,F). The widespread expression of Myc-nick in tumor samples raises the possibility that this form of Myc may contribute to a fundamental aspect of tumor cell biology.

\section{Myc-nick expression in colon cancer}

One of the major events involved in the development of colorectal cancer is the aberrant activation of the Wnt signaling pathway, resulting in accumulation of $\beta$-catenin in the nucleus, where it functions as a transcriptional activator of c-myc. Because of the essential role played by Myc in the initiation of colon cancer in mouse models (Sansom et al. 2007) and the elevated levels of Myc-nick in colon cancer cells, we further analyzed the localization of Myc in human colorectal cancer biopsies. We examined 19 independent samples by immunohistochemistry using antibodies against the $\mathrm{C}$ terminus of Myc (such as 9E10), which recognizes only full-length Myc, or the $\mathrm{N}$ terminus of Myc (such as 274), which recognizes both full-length Myc and Myc-nick (Fig. 1A). Overall, we found that the antibodies against the $\mathrm{N}$ terminus of $\mathrm{Myc}$ detected a signal in both the nucleus and the cytoplasm, while an antibody against the $\mathrm{C}$ terminus (9E10) detected predominantly nuclear staining and, less frequently, low levels of cytoplasmic staining (Fig. 1J,K). The immunohistochemistry results obtained with both antibodies for all 19 human colorectal tumors are listed in Supplemental Table S1. We found significant variability in immunostaining for Myc among the tumors and within each tumor. For example, some areas of a given tumor displayed exclusively nuclear staining, while others exhibited predominantly cytoplasmic staining. There were still other areas that clearly appeared to have both nuclear and cytoplasmic staining for Myc (Fig. 1K). We observed both nuclear and cytoplasmic staining within proximal areas of the same tumor, indicating that the cytoplasmic staining for Myc is not an artifact of fixation (Fig. 1K).

\section{Hypoxia and nutrient deprivation lead to cytoplasmic accumulation of Myc and conversion into Myc-nick}

Different areas within tumors are known to be exposed to variable levels of nutrients and oxygen, depending on their proximity to blood vessels and stroma (Mucaj et al. 2012). Therefore, we considered that the variability in the presence of Myc forms could be caused by local heterogeneity in the microenvironment, leading to increased conversion of Myc into Myc-nick. We observed that culturing cells for prolonged periods without changing the culture medium caused an increase in the levels of Myc-nick (Fig. 2F), most likely due to depletion of nutrients from the culture medium, since culturing subconfluent proliferating cells in confluent cell-conditioned medium also resulted in increased Myc-nick levels
(Supplemental Fig. S1C). Interestingly, recent reports show that Myc levels are down-regulated in colon cancer cells under hypoxia as a means of preventing Myc-induced cell death (Li et al. 2009; Wong et al. 2013).

To address whether conditions that limit cellular proliferation within tumors, such as hypoxia and nutrient deprivation, could trigger the conversion of Myc into Myc-nick, we studied colon cancer cells cultured under limiting amounts of oxygen $\left(\mathrm{O}_{2}\right)$ and a carbon source. We found that hypoxia $\left(1 \% \mathrm{O}_{2}\right)$ or deprivation of glucose and glutamine causes an increase in the levels of Myc-nick in the cytoplasm and a decrease in nuclear full-length Myc (Fig. 2A,B,G). While removing both glucose and glutamine at $21 \% \mathrm{O}_{2}$ leads to a significant increase in Myc-nick levels, under hypoxic conditions, glucose starvation was sufficient to induce the retention of full-length Myc in the cytoplasm and its conversion into Myc-nick (Fig. 2I).

The increase in Myc-nick levels under stress conditions is not due to enhanced calpain proteolytic activity toward Myc because cytoplasmic extracts isolated from cells grown at $1 \% \mathrm{O}_{2}$ or in the absence of glucose and glutamine do not display higher proteolytic activity than control cells (Fig. 2C,J). Furthermore, the presence of cytoplasmic full-length Myc under hypoxia (Fig. 2A) was not due to altered CRM1-dependent nuclear transport of Myc because blocking CRM1 with leptomycin B had no effect on the cytoplasmic pool of Myc (Fig. 2D). Instead, leptomycin $\mathrm{B}$, which at $21 \% \mathrm{O}_{2}$ causes retention of full-length Myc in the nucleus, resulted in a reduction in the levels of nuclear full-length Myc under hypoxia. This is most probably due to increased proteasomal degradation of Myc in the nucleus, as previously reported $(\mathrm{Li}$ et al. 2009; Wong et al. 2013). In support of those reports, we found an increase in the phosphorylation of Myc Thr58 (P-T58) under hypoxia, an event required to prime Myc for Fbw7-mediated degradation (Fig. 2D). The multiple bands detected in the P-T58 Western blot are probably derived from a combination of phosphorylated Myc and Myc-nick recognized by the antibody against phosphorylated T58 and S62.

While inhibiting calpain activity at $21 \% \mathrm{O}_{2}$ causes an accumulation of full-length Myc in the nucleus, under hypoxia, calpain inhibitors cause an accumulation of fulllength Myc in the cytoplasm (Fig. 2E). This indicates that hypoxia prevents nuclear translocation of newly synthesized Myc, exposing it to the activity of cytoplasmic calpains and thereby producing Myc-nick. Similarly, the increase in Myc-nick levels that occurs in the absence of both glucose and glutamine appears to be related to the retention of full-length Myc in the cytoplasm. When cells are fed with complete medium, there is a rapid increase in Myc levels caused by growth factor-induced transcriptional up-regulation of Myc. This newly synthesized Myc accumulates rapidly in the nucleus, as early as $2 \mathrm{~h}$ following refeeding of the cells (Fig. 2H). However, when cells are fed with medium lacking glucose and glutamine, full-length Myc accumulates in the cytoplasm, where it functions as substrate for the production of Mycnick (Fig. 2H). 
A

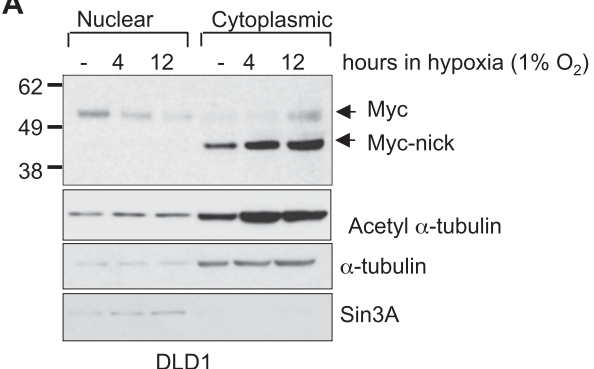

B
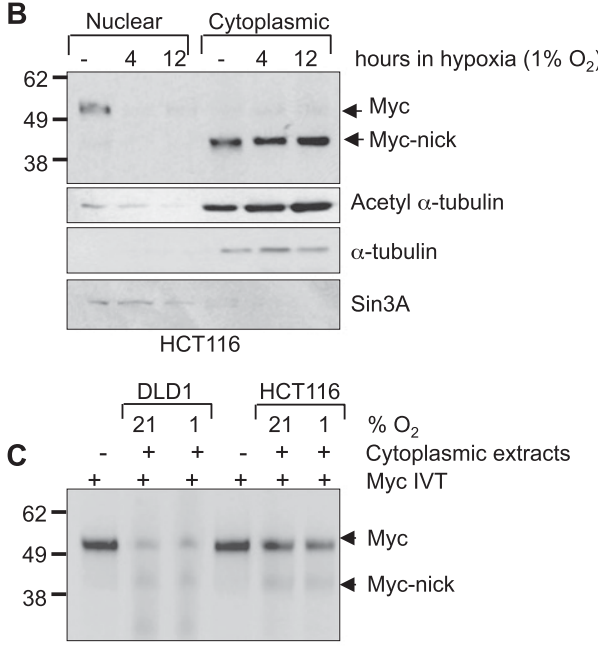

D
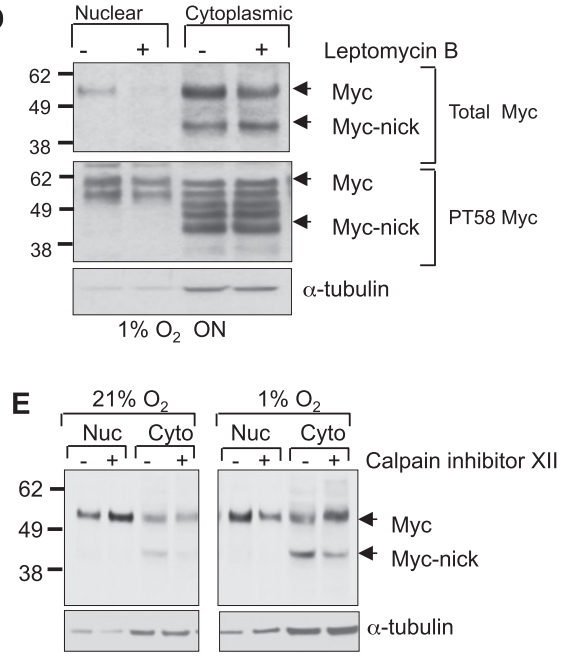

$\mathbf{F}$

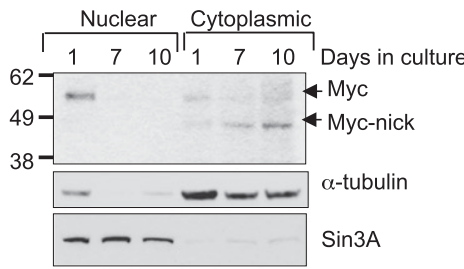

G

H

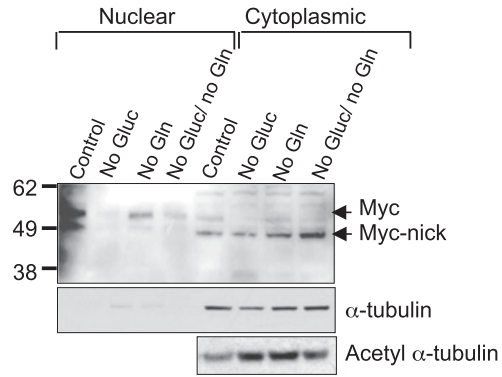

Complete medium No Gluc/ no Gln
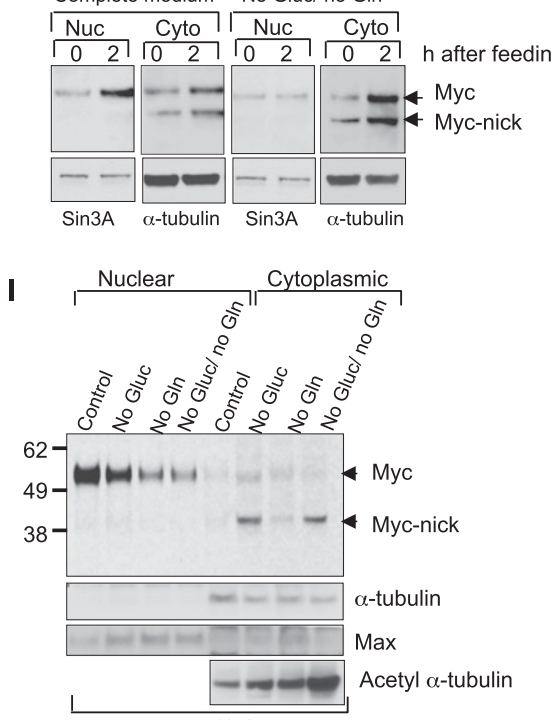

$8 \mathrm{~h} \quad 1 \% \mathrm{O}_{2}$

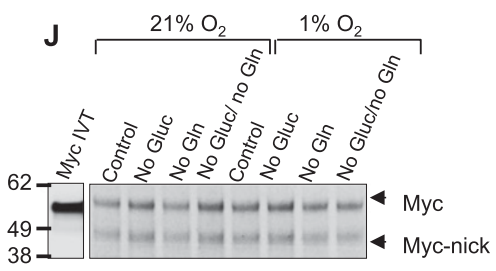

Figure 2. Myc-nick levels are elevated under stress conditions such as hypoxia and nutrient deprivation in colon cancer cells. $(A, B)$ DLD1 and HCT116 cells were grown to confluency at $21 \% \mathrm{O}_{2}$ for $48 \mathrm{~h}$ and then transferred to hypoxia $\left(1 \% \mathrm{O}_{2}\right)$ for the indicated time points. (C) Calpainmediated cleavage of Myc is not enhanced by hypoxia. DLD1 and HCT116 cells were cultured overnight at $21 \%$ and $1 \%$ O $\mathrm{O}_{2}$. Cytoplasmic extracts were prepared in the absence of protease inhibitors and used to cleave S35-IVT Myc in vitro for $2 \mathrm{~h}$. (D) Blocking nuclear export with leptomycin B does not affect Myc-nick levels under hypoxia. DLD1 cells were grown to confluency and placed in hypoxic conditions for $12 \mathrm{~h}$ in the presence or absence of leptomycin B. $(E)$ Full-length Myc accumulates in the cytoplasm of cells cultured under hypoxia. DLD1 cells were grown overnight at $21 \%$ or $1 \% \mathrm{O}_{2}$ in the presence or absence of calpain inhibitor XII. (F) Myc-nick levels are increased with prolonged culture time. DLD1 cells were harvested 1, 7, and $10 \mathrm{~d}$ after plating without replacing culture medium and processed for Western blot. (G) Confluent cultures of DLD1 cells were incubated in DMEM, DMEM lacking glucose (No Gluc), DMEM lacking glutamine (No Gln), or DMEM lacking both glucose and glutamine (No Gluc/no Gln) for $6 \mathrm{~h}$ before fractionation. $(H)$ Glucose and glutamine deprivation leads to rapid accumulation of full-length Myc in the cytoplasm. Confluent cultures of DLD1 cells were incubated with DMEM or DMEM lacking glucose and glutamine at $21 \% \mathrm{O}_{2}$ for $2 \mathrm{~h}$. (I) Confluent cultures of DLD1 cells were incubated with DMEM, DMEM lacking glucose, DMEM lacking glutamine, or DMEM lacking both glucose and glutamine at $1 \% \mathrm{O}_{2}$ for $8 \mathrm{~h}$. (/) Glucose and glutamine deprivation does not affect Myc cleavage in vitro. Cells were treated as in $I$; the cytoplasmic extracts were prepared in the absence of protease inhibitors and used to cleave S35-IVT Myc in vitro. 
Myc-nick protects cells from death caused by nutrient deprivation

We next asked whether Myc-nick plays an active role in tumorigenesis by introducing a vector-expressing Mycnick, as previously described (Conacci-Sorrell et al. 2010). The overexpression of Myc-nick does not significantly alter proliferation (a transcriptional function of $\mathrm{Myc}$ ) when expressed in Rat1 myc-null fibroblasts (Fig. 3A). However, Myc-nick expression (Fig. 3C) enhances the survival of colon cancer cells grown in the absence of glucose and glutamine (Fig. 3B). This was measured by a reduction in trypan blue-negative cells (Fig. 3B) and a decrease in the levels of cleaved caspase 3 (Fig. 3D). In addition, in contrast to control cells, Myc-nick-expressing cultures preserved cell-cell adhesion, as evidenced by surface $\beta$-catenin and E-cadherin staining, when grown in the absence of glucose and glutamine (Supplemental Fig. S2B,C). Overall, Myc-nick expression significantly delayed death of colon cancer cells in the absence of carbon sources, and most Myc-nick-expressing cells died 2-3 d after control cells (Fig. 3B). In normal rat fibroblasts, the expression of Myc-nick caused a small reduction in the levels of cleaved caspase 3 when cells where cultured in complete medium (Supplemental Fig. S4F). However, Myc-nick expression was not sufficient to prevent death induced by lack of glucose and glutamine in these nontransformed cells, thus indicating that Myc-nick cooperates with other prosurvival pathways that are activated in colon cancer cells.

Elevated levels of full-length Myc promote programmed cell death under starvation conditions (Evan et al. 1992). Serum starvation caused death in DLD1 cells expressing high levels of Myc, particularly in the presence of a calpain inhibitor. However, Myc-nick-expressing cells displayed significant resistance to apoptosis, as measured by flow cytometry of DAPI-stained (Fig. 3E) and PI-stained (data not shown) cells and the levels of cleaved caspase 3 (Fig. 3C, bottom panels). We presume that calpain inhibition leads to an accumulation of full-length Myc, which is responsible for promoting apoptosis.

\section{Myc-nick enhances anchorage-independent growth}

Anchorage-independent growth is a crucial step in the development of malignancies (Freedman and Shin 1974) and a hallmark of many tumors (Hanahan and Weinberg 2011). We tested Myc-nick-expressing DLD1 cells for anchorage-independent growth in soft agar and observed a significant increase in the number of mature colonies (Fig. 3F). Myc-nick and control cultures produced colonies of similar size (data not shown), suggesting that Mycnick permits a larger number of cells to initiate a colony in soft agar. Strikingly, Myc-nick increased by 3.2-fold the number of colonies in soft agar when cells were cultured at $1 \% \mathrm{O}_{2}$, as opposed to a 1.7-fold increase when cultures were grown at $21 \% \mathrm{O}_{2}$ (Fig. $3 \mathrm{~F}$ ). This is in agreement with our previous observation that Myc-nick protects cells against apoptosis under stress conditions (Fig. 3B,D). Consistent with their reduced cell death and increased survival, Myc-nick-expressing cells displayed diminished p53 levels (Fig. 3I).

When Myc-nick-expressing cells were cultured for several days after reaching confluency, we observed a large number of foci growing over the monolayer, an indication of loss of contact inhibition and acquisition of a more malignant phenotype (Fig. 3G). We noted that the foci formed by Myc-nick-expressing cells contain nocodazole-resistant acetylated microtubules (Fig. 3H), consistent with the induction of $\alpha$-tubulin acetylation by Myc-nick in colon cancer cells (Fig. 3I) and other cell types (Conacci-Sorrell et al. 2010). Acetylation of $\alpha$-tubulin, a likely mediator of Myc-nick's functions (ConacciSorrell et al. 2010) was enhanced by Myc-nick expression in DLD1 cells independent of the activity of deacetylases (Fig. 3J), indicating that Myc-nick mediates acetylation of $\alpha$-tubulin in these cells.

\section{Myc-nick promotes genomic instability}

In addition to preventing cell death, overexpression of Myc-nick induced changes in the general appearance of proliferating cultures, marked by an increase in multinucleated cells and multipolar spindle formation (Supplemental Fig. S4A-D). Myc-nick expression caused an accumulation of the DNA damage marker phosphorylated $\mathrm{H} 2 \mathrm{AX}(\gamma \mathrm{H} 2 \mathrm{AX})$ in DLD1 (Supplemental Fig. S4E,H) and SW480 (Supplemental Fig. S4G) cells when grown under carbon source deprivation but not when cultured in complete medium (Supplemental Fig. S5G,H). This suggests that Myc-nick facilitates the survival of cells damaged under stress conditions but does not itself cause DNA damage.

An important source of DNA damage is UV radiation, and we found that UV treatment promoted the conversion of Myc into Myc-nick within 5 min of irradiation in Rat1 fibroblasts (Supplemental Fig. S3A). Moreover, the expression of Myc-nick increases the survival of these cells after UV radiation (Supplemental Fig. S3B).

\section{The conversion of Myc into Myc-nick restricts cell death following nutrient and growth factor deprivation}

To address whether the conversion of Myc into Myc-nick is important in limiting cell death, we blocked the cleavage of endogenous Myc using calpain inhibitors and additionally used Myc mutants that are resistant to calpain-mediated cleavage. Preventing Myc cleavage with inhibitors such as calpeptin, calpain inhibitor XII, and calpain inhibitor VI accelerates cell death under glucose and glutamine deprivation in proliferating wildtype cells and even more profoundly in Myc-overexpressing cells. This was visualized by immunostaining and Western blot for cleaved caspase 3 (Fig. 4A-C; Supplemental Fig. S2A). We obtained a similar increase in cell death when we treated colon cancer cells with calpain inhibitors while the cells were cultured in the absence of growth factors (Fig. 3C,E).

We demonstrated previously that a mutation in Myc that limits calpain cleavage (Myc $\Delta 291-300$ ) prevented muscle cell differentiation by causing extensive cell 
A

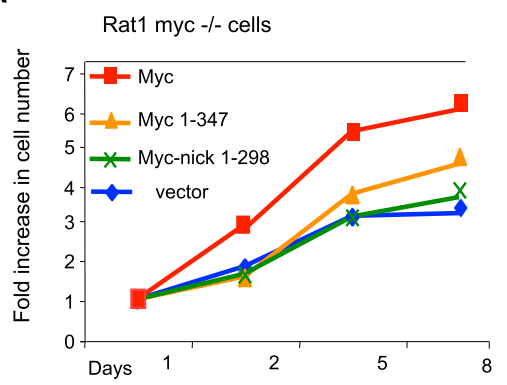

C
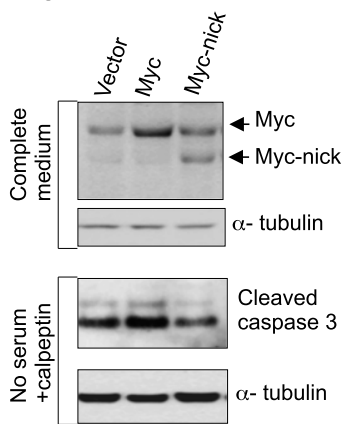

E

\begin{tabular}{|l|l|}
\hline $\begin{array}{l}\text { Sample } \\
\text { No serum }\end{array}$ & Sub G1 DNA \\
\hline vector & $11.8 \%$ \\
\hline Myc & $25.3 \%$ \\
\hline Myc-nick & $9.2 \%$ \\
\hline $\begin{array}{l}\text { vector }+ \\
\text { Calpeptin }\end{array}$ & $62.1 \%$ \\
\hline $\begin{array}{l}\text { Myc }+ \\
\text { Calpeptin }\end{array}$ & $71.9 \%$ \\
\hline $\begin{array}{l}\text { Myc-nick }+ \\
\text { Calpeptin }\end{array}$ & $19 \%$ \\
\hline
\end{tabular}

I

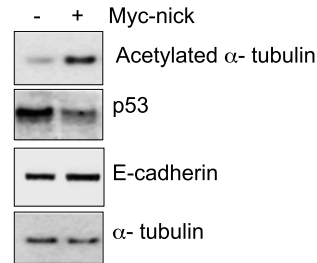

D
B
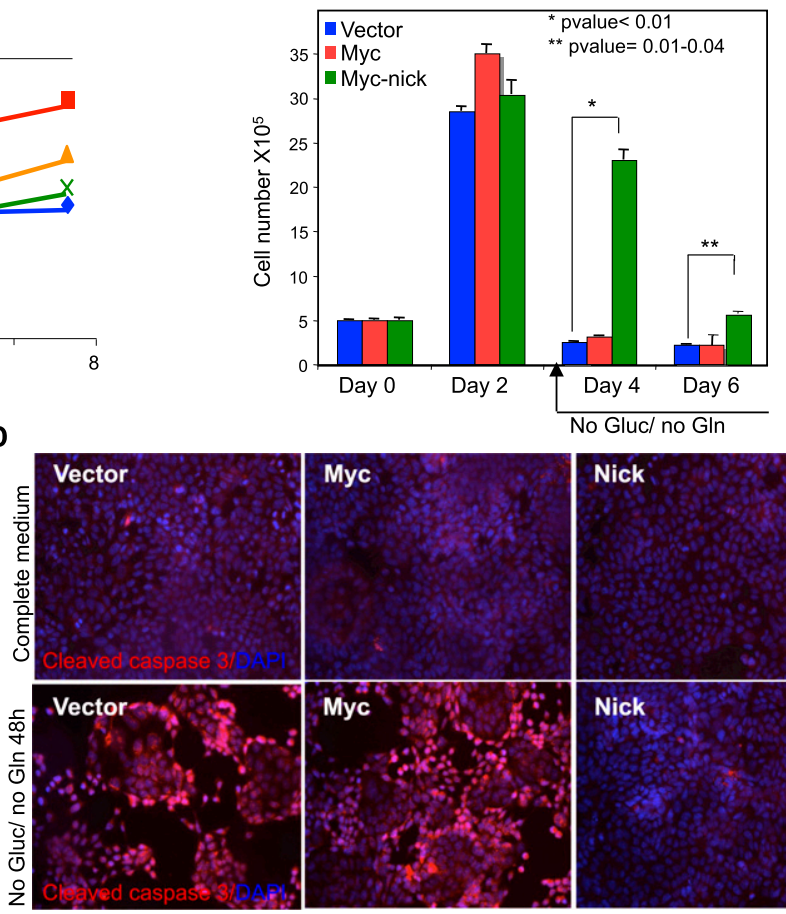

Myc

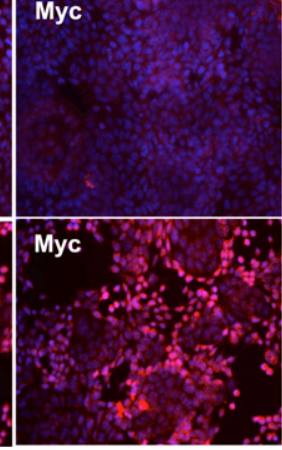

\section{Nick}

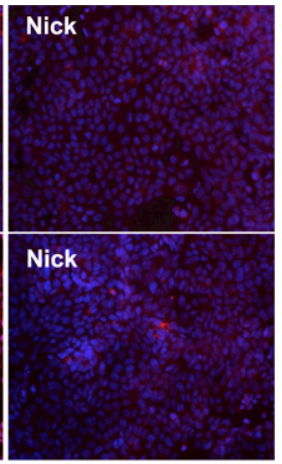

G
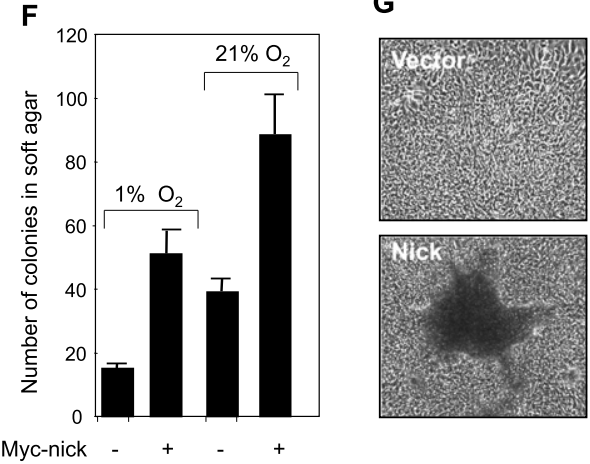

H

Acetylated $\alpha$-tubulin Vector.
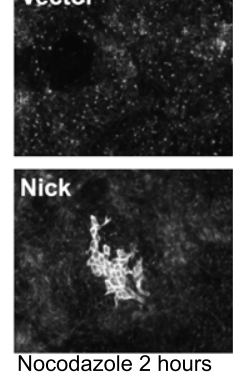

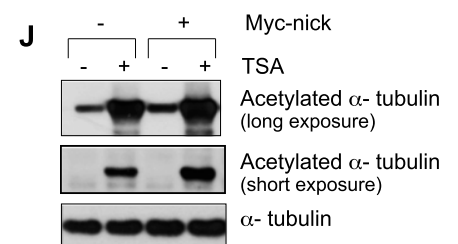

Figure 3. Myc-nick protects colon cells from death induced by nutrient deprivation. $(A)$ Rat1 myc-null fibroblasts expressing vector, Myc, Myc lacking the DNA-binding domain (amino acids 1-347), and Myc-nick (amino acids 1-298) were grown in the presence of serum. Cells $\left(5 \times 10^{3}\right)$ were seeded in 12-well plates in triplicate, counted $10 \mathrm{~h}$ after seeding, and then counted every $2 \mathrm{~d}$. Every time point was normalized to the 10-h time point. $(B)$ Ectopic expression of Myc-nick in DLD1 colon cancer cells increased survival in the absence of glucose and glutamine. DLD1 cells $\left(5 \times 10^{5}\right)$ expressing vector, Myc, and Myc-nick were seeded on 35-mm dishes and counted after $2 \mathrm{~d}$. At that point, the medium was replaced with DMEM lacking glucose and glutamine, and the trypan blue-negative cells were counted every $2 \mathrm{~d}$. (C) Western blot of DLD1 cells expressing vector, Myc, and Myc-nick were grown in complete medium (top panels) or in the presence of calpeptin and absence of serum (bottom panels). (D) Cells treated as in B were fixed on day 4 and then stained for cleaved caspase 3 and DAPI. (E) DLD1 cells expressing vector, Myc, and Myc-nick were grown to confluency, transferred to DMEM without serum in the presence or absence of calpeptin for $48 \mathrm{~h}$, fixed in ethanol, DAPI-stained, and analyzed by flow cytometry to measure the percentage of apoptotic cells. $(F)$ Myc-nick enhances anchorage-independent growth. DLD1 cells $\left(15 \times 10^{3}\right)$ expressing vector or Myc-nick were plated in 35-mm soft agar plates and placed at either $21 \%$ or $1 \% \mathrm{O}_{2}$. The number of colonies was counted after $2 \mathrm{wk}$. $(G)$ Myc-nick-expressing cells form multiple foci over the monolayer when cultured at high densities. A single focus is shown. $(H)$ Foci formed on confluent cultures of Myc-nick-expressing cells are enriched in stable microtubules that cannot be disrupted by $2 \mathrm{~h}$ of treatment with nocodazole. $(I)$ Myc-nick expression induces acetylation of $\alpha$-tubulin and decreases p53 levels. ( $/$ ) Induction of $\alpha$-tubulin acetylation by Myc-nick is independent of HDAC activity. DLD1 cells expressing vector and Myc-nick were grown to confluency and then treated with trichostatin A (TSA) for $6 \mathrm{~h}$. 

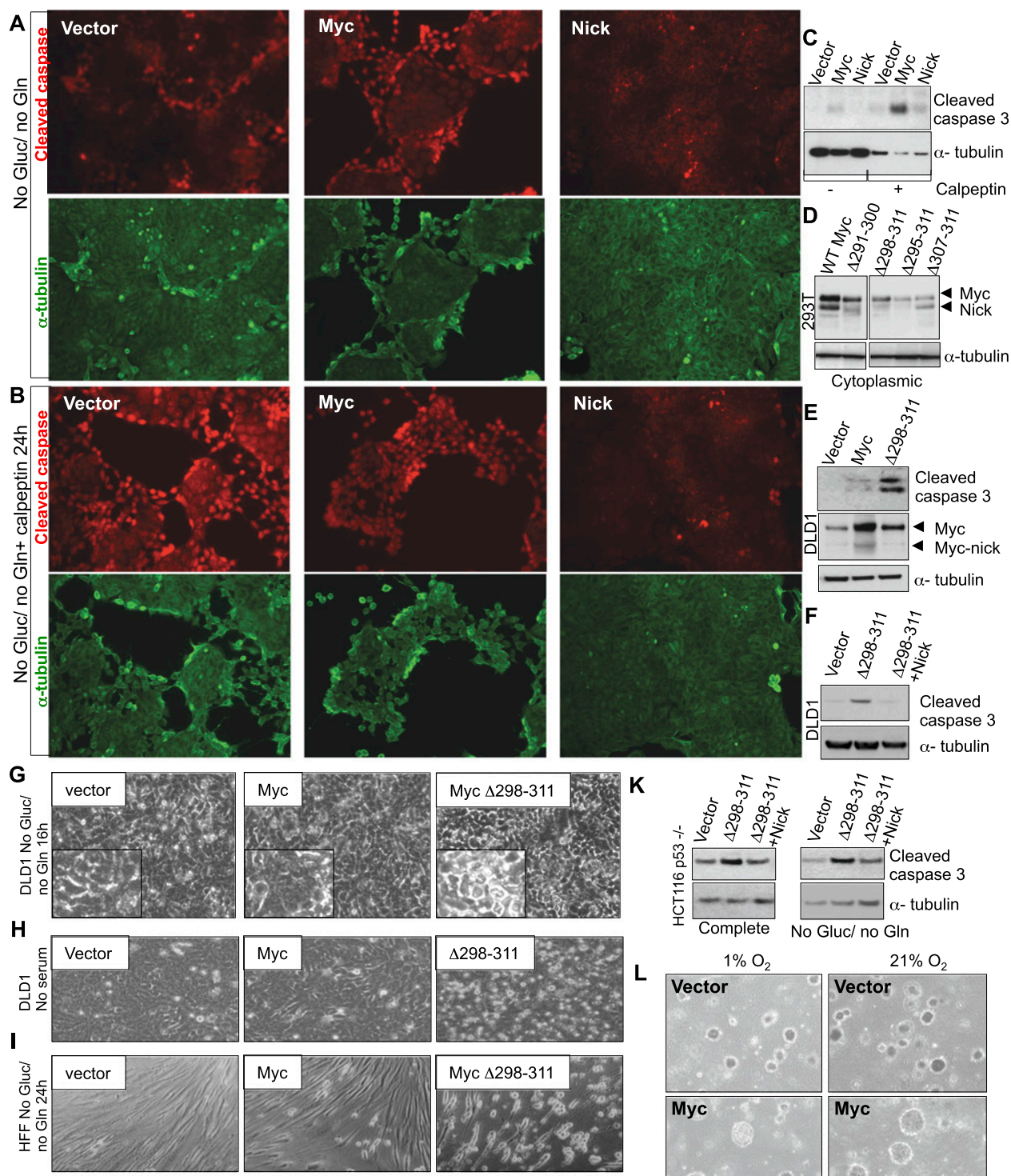

$\mathbf{J}$
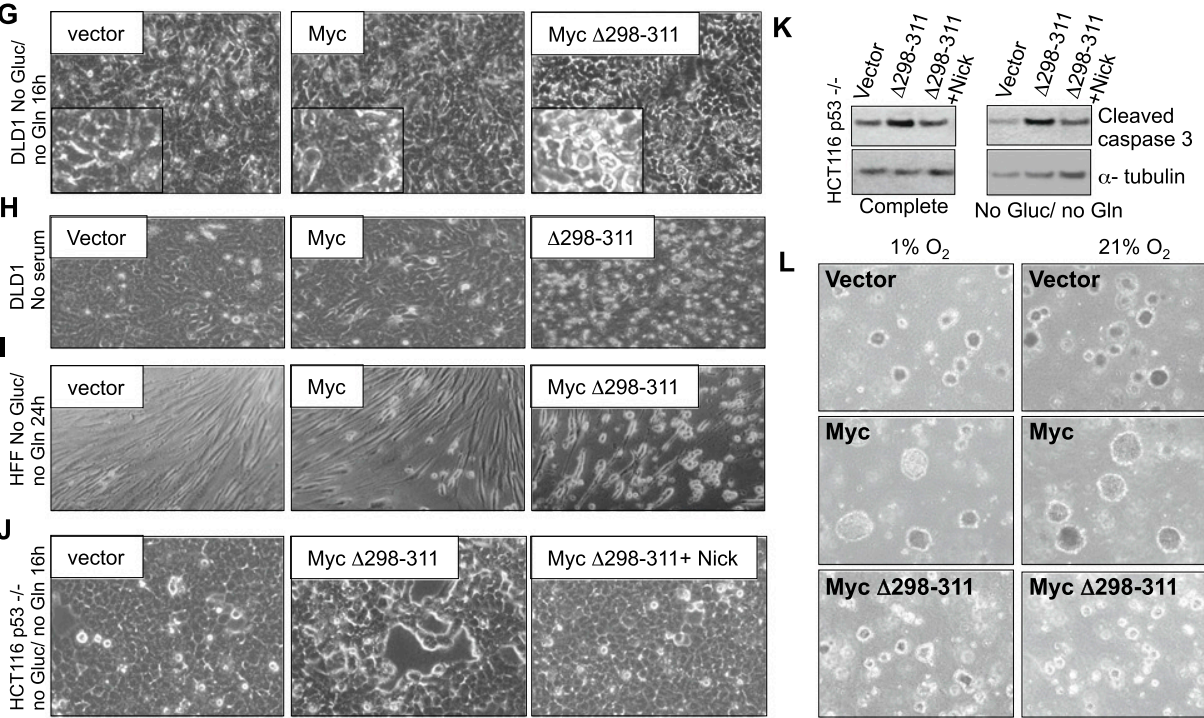

Gluc/ no Gln

Figure 4. The cleavage of Myc promotes cell survival under nutrient and growth factor deprivation. (A) DLD1 cells expressing vector, Myc, or Myc-nick were grown in DMEM lacking glucose and glutamine for $24 \mathrm{~h}$ and immunostained for cleaved caspase 3 and $\alpha$-tubulin. (B) Preventing Myc cleavage increases cell death. DLD1 cells expressing vector, Myc, and Myc-nick were grown in DMEM without glucose or glutamine in the presence of calpeptin for $12 \mathrm{~h}$ and immunostained for $\alpha$-tubulin and cleaved caspase 3. (C) Western blot of cells treated as in $B$. (D) The deletion mutant Myc $\Delta 298-311$ is resistant to proteolytic cleavage and does not produce Myc-nick when transfected in 293T cells. (E) The cleavage-resistant mutant Myc $\Delta 298-311$ promotes more apoptosis than wild-type (WT) Myc. Confluent cultures of DLD1 cells expressing vector, Myc, and Myc $\Delta 298-311$ cultured in complete DMEM were processed for Western blot. $(F, G)$ DLD1 cells expressing vector, Myc, and Myc $\Delta 298-311$ were grown to confluency, transferred to DMEM without glucose and glutamine for $24 \mathrm{~h}$, and then photographed $(G)$ or processed for Western blot $(F)$. $(H)$ The Myc mutant $\Delta 298-311$ increases cell death under serum starvation, as determined by cell morphological changes. DLD1 cells expressing vector, Myc, or Myc $\Delta 298-311$ were grown to confluency, transferred to DMEM without serum for $48 \mathrm{~h}$, and then photographed. (I) HFF cells expressing vector, Myc, and Myc $\Delta 298-311$ were grown to confluency, transferred to DMEM lacking glucose and glutamine for $24 \mathrm{~h}$, and then photographed. $(J, K)$ Myc-nick expression rescues death induced by the Myc $\Delta 298-311$ mutant. p53 ${ }^{-1}$ HCT116 cells expressing vector, Myc $\Delta 298-311$, and Myc $\Delta 298-311+$ Myc-nick were incubated in DMEM without glucose and glutamine for $24 \mathrm{~h}$ and then photographed $(J)$ or processed for Western blot $(K)$. $(L)$ DLD1 cells $\left(45 \times 10^{3}\right)$ expressing vector, Myc, Myc $\Delta 298-311$, or Myc-nick were plated in 35-mm soft agar plates, placed at either $21 \%$ or $1 \% \mathrm{O}_{2}$, and photographed after $2 \mathrm{wk}$. 
death of myoblasts (Conacci-Sorrell et al. 2010). We now generated new mutants and found that a deletion of amino acids 298-311 ( $\Delta 298-311)$ and a larger deletion, $\Delta 295-311$ (see Fig. 1A), significantly reduce Myc cleavage when compared with other mutants in 293T and DLD1 cells (Fig. 4D,E). Importantly, Myc $\Delta 298-311$ is not expressed at higher levels than wild-type Myc (Fig. 4E; Supplemental Fig. S5B) and is predominantly localized to the nucleus (Supplemental Fig. S5A). However, it was not possible to generate a culture of cells expressing high levels of the cleavage-resistant mutant of Myc, suggesting that cells expressing high levels of $\Delta 298-311$ have sharply diminished viability. The expression of Myc $\Delta 298-311$ in DLD1 cells increases apoptosis in the absence of glucose and glutamine when compared with wild-type Myc, as measured by cleaved caspase 3 (Fig. 4E) and loss of cellcell adhesion (Fig. 4G). Moreover, the $\Delta 298-311$ mutant promoted an increase in cell death in the absence of serum that was significantly greater than apoptosis induced by wild-type Myc (Fig. 4H). Myc $\Delta 298-311$ also increased cell death in HFF cells (Fig. 4I) as well as in C2C12 myoblasts (Supplemental Fig. S5C). While endogenous Myc and Myc-nick can cooperate with MyoD to transdifferentiate fibroblasts into multinucleated myotubes, coexpression of Myc $\Delta 298-311$ prevents transdifferentiation and triggers cell death (Supplemental Fig. S5D). Importantly, as measured by cleaved caspase 3, the cell death induced by the $\Delta 298-311$ mutant can be attenuated by coexpression of Myc-nick in DLD1 cells (Fig. 4F) and HCT116 p53-null cells (Fig. 4K). When cells expressing Myc $\Delta 298-311$ were grown in soft agar, initially, the same number of cells gave rise to young colonies as wild-type Myc-expressing cells (data not shown). However after $2 \mathrm{wk}$, the colonies produced by cells expressing Myc $\Delta 298-311$ at $21 \%$ or $1 \% \mathrm{O}_{2}$ stopped growing and disintegrated, while colonies expressing wild-type Myc continued growing (Fig. 4L). Spheroid cultures have been reported to develop hypoxic areas in the center once spheres reach $500 \mu \mathrm{m}$ (Vinci et al. 2011). Similarly, when colon cancer colonies reach a critical size, cells in the inner part of the colonies are exposed to limiting amounts of nutrients and oxygen, resulting in cell death. At that point, colonies formed by cells expressing Myc $\Delta 298-311$ undergo apoptosis. Because the Myc $\Delta 298-311$ mutant cannot be cleaved to produce Myc-nick, cells remain with an excess of uncleavable full-length Myc that promotes apoptosis. Endogenous Myc-nick is not sufficient to prevent death of cells overexpressing Myc $\Delta 298$ 311 , but overexpressed Myc-nick partially rescues.

\section{The Myc box II region (MBII) is required} for Myc-nick-induced cell survival

MBII is a major determinant of Myc's transcriptional function (see Fig. 1A). It is the site of recruitment of coactivator complexes containing HATs such as GCN5 (McMahon et al. 2000) and TIP60 (Frank et al. 2003) via the adaptor protein TRRAP. Myc-nick contains MBII and retains the ability to bind HATs. Moreover, association of Myc-nick with HATs is involved in the induction of $\alpha$-tubulin acetylation by Myc-nick /Conacci-Sorrell et al. 2010). Silencing TRRAP and GCN5, but not TIP60, increased death of Myc-nick-expressing cells cultured for $48 \mathrm{~h}$ in the absence of glucose and glutamine (Supplemental Fig. S7A,B). To directly address the relevance of MBII to Myc-nick-facilitated cell survival, we deleted amino acids 106-143, encompassing MBII within Mycnick (Myc-nick $\triangle \mathrm{MBII}$ ), and studied the response of cells expressing this mutant to stress-induced cell death.

We found that removing MBII, while having no effect on Myc-nick expression levels (Fig. 5F), blocked Mycnick's ability to protect cells from death induced by nutrient deprivation (Fig. 5B-E). Moreover, deleting MBII also reduced the ability of Myc-nick to promote growth in soft agar, particularly under hypoxia (Fig. 5D). Immunofluorescence for cell adhesion molecules such as E-cadherin and $\beta$-catenin showed that Myc-nick-expressing cells, but not control or Myc-nick $\Delta$ MBII-expressing cells, preserved an epithelial appearance when cultured in medium without glucose and glutamine (Supplemental Fig. S2D). However, both cell lines displayed similar morphology when cultured in complete growth medium.

Myc-nick $\triangle$ MBII behaves like a loss-of-function mutation because it does not protect cells from death under serum starvation and glucose and glutamine deprivation (Fig. 5A-E). In contrast to Myc-nick, the $\Delta$ MBII mutant fails to block cleavage of caspase 3 (Fig. 5E,F), fails to augment acetylation of $\alpha$-tubulin at both $1 \%$ and $21 \% \mathrm{O}_{2}$ (Fig. 5F), and reduces the levels of $\mathrm{P} \gamma \mathrm{H} 2 \mathrm{AX}$ (Supplemental Fig. S4H). Taken together, these results suggest that the binding of Myc-nick to acetyltransferases is necessary for Myc-nick's ability to promote cell survival and that acetylation of $\alpha$-tubulin-and probably other cytoplasmic proteins-contributes to this activity of Myc-nick.

\section{Myc-nick increases tumor cell survival in response to chemotherapeutic agents}

Because Myc-nick promotes cell survival under several different types of stress and is highly expressed in some tumor cells, we asked whether Myc-nick expression confers resistance to chemotherapeutic agents. We treated DLD1 cells expressing vector, Myc-nick, and Myc-nick $\Delta$ MBII with etoposide, cisplatin, oxaliplatin, and imatinib. We found that Myc-nick, but not vector alone or the $\Delta \mathrm{MBI}$ mutant, significantly increased cell survival within a 10-fold range of drug concentrations (Fig. 6A,E). Similar to the results obtained with cells cultured in the absence of glucose and glutamine, Myc-nick-expressing cells survived twice as long as control cells in the presence of chemotherapeutic agents. Myc-nick also prevented the cleavage of caspase 3 , as measured after $24 \mathrm{~h}$ of incubation with etoposide, cisplatin, and imatinib (Fig. 6B-D). Treatment with chemotherapeutic drugs such as etoposide did not significantly alter the levels of endogenous Myc-nick (Supplemental Fig. S7C).

While untreated Myc-nick-expressing cells display lower levels of p53 (Fig. 3I), we found that chemotherapeutic agents induce p53 to the same extent in Myc-nick and control cultures (Supplemental Fig. S7A). Further- 
A
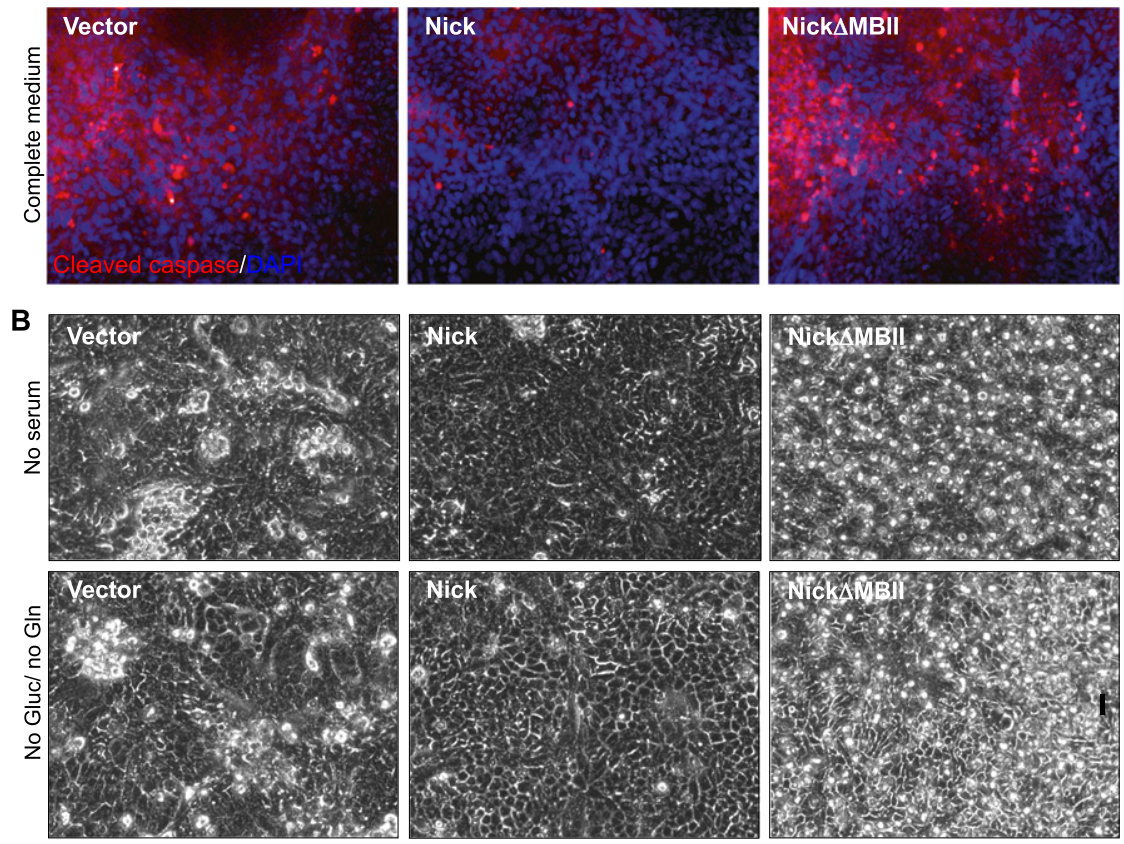

C
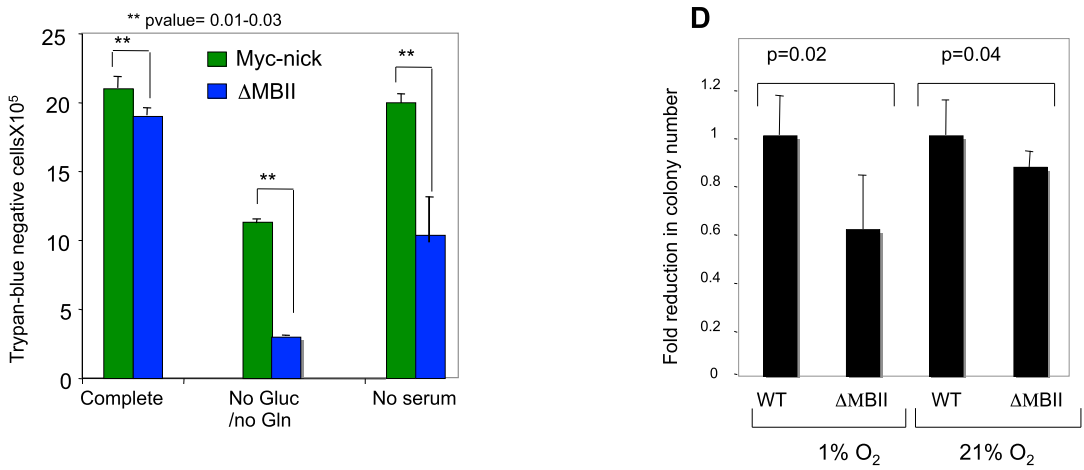

E

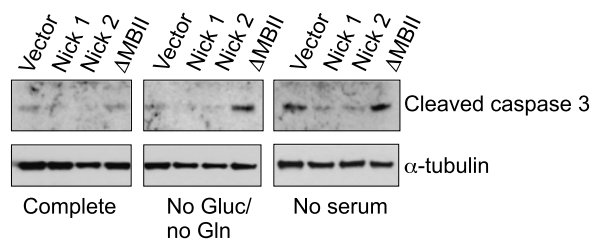

$\mathbf{F}$

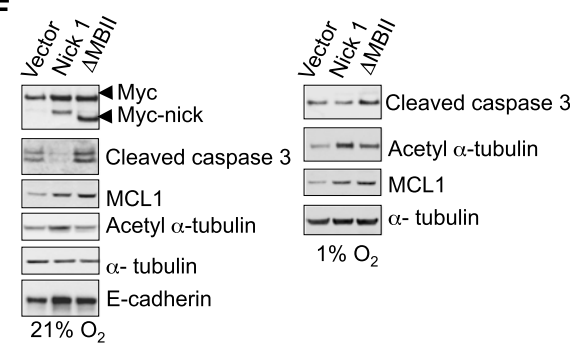

Figure 5. MBII is required for Myc-nick-induced cell survival under stress. (A) DLD1 cells expressing vector, Myc-nick, and Myc-nick $\triangle$ MBII were grown in complete medium for $48 \mathrm{~h}$, fixed, and stained for cleaved caspase 3 and DAPI. (B,C) Cells expressing vector, Mycnick, and Myc-nick $\triangle$ MBII grown in complete medium for $48 \mathrm{~h}$ were kept in complete medium or transferred to medium lacking glucose and glutamine or lacking serum. Cells were photographed $(B)$ or stained with trypan blue and counted $(C)$. $(D)$ Deletion of MBII reduces growth in soft agar. DLD1 cells $\left(15 \times 10^{3}\right)$ expressing vector, Myc-nick, and Myc-nick $\Delta$ MBII were plated in 35-mm soft agar plates and placed at either $21 \%$ or $1 \% \mathrm{O}_{2}$ for $3 \mathrm{wk}$. The bars represent the reduction in the number of colonies produced by DLD1 cells expressing Myc-nick $\triangle$ MBII. The values obtained for cells expressing wild-type (WT) Myc-nick were set to 1 . The average number of colonies for wildtype Myc-nick and $\triangle$ MBII Myc-nick were 19.6 and 12 at $1 \% \mathrm{O}_{2}$ and 34.6 and 28 at $21 \% \mathrm{O}_{2}$. $(E)$ Western blot for cleaved caspase 3 of DLD1 cells expressing vector, Myc-nick, and Myc-nick $\triangle \mathrm{MBII}$ grown in complete medium, medium without serum, or medium without glucose and glutamine for $24 \mathrm{~h}$. Nick1 and Nick2 are two independently generated cultures of DLD1 cells expressing Myc-nick. $(F)$ Western blot of DLD1 cells expressing vector, Myc-nick, and Myc-nick $\triangle$ MBII grown in complete medium for $48 \mathrm{~h}$ at either $21 \%$ or $1 \% \mathrm{O}_{2}$.

more, siRNA-mediated silencing of p53 had no significant effect on the survival of Myc-nick-expressing cells (data not shown). Moreover, HCT116 p53-/- cells were also protected from death by nutrient deprivation and chemotherapeutic agents upon expression of Myc-nick (Supplemental Fig. S7B). Interestingly, Myc-nick-expressing 


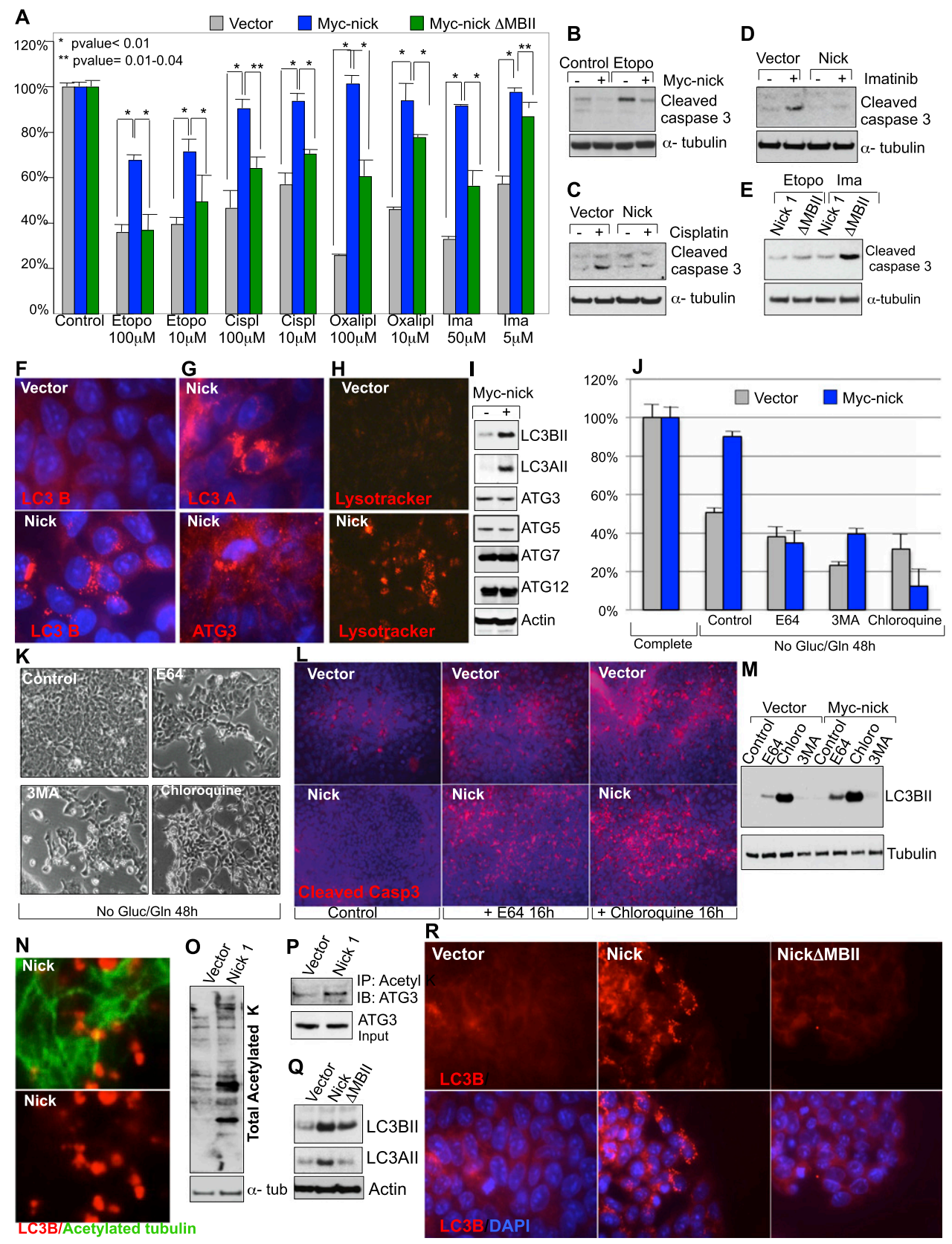

Figure 6. Myc-nick protects DLD1 cells from death induced by chemotherapeutic agents and induces autophagy. $(A)$ Confluent cultures of DLD1 cells expressing vector or Myc-nick were incubated for $24 \mathrm{~h}$ in the presence of etoposide, cisplatin, oxaliplatin, and imatinib. $(B-D)$ Confluent cultures of DLD1 cells were incubated for $24 \mathrm{~h}$ in the presence of etoposide $(B)$, cisplatin $(C)$, and imatinib $(D)$ and processed for Western blot for cleaved caspase 3. (E) MBII is necessary for Myc-nick-induced resistance to chemotherapeutic drugs. Confluent cultures of DLD1 cells were incubated for $24 \mathrm{~h}$ in the presence of etoposide and imatinib. $(F-I)$ Myc-nick induces autophagosome formation. $(F)$ DLD1 cells expressing vector and Myc-nick were grown to $\sim 80 \%$ confluency, methanol-fixed, and stained for LC3B. $(G)$ DLD1 cells expressing Myc-nick were grown as in $F$ and stained for LC3A and ATG3. (H) DLD1 cells expressing vector and Myc-nick were grown to $\sim 80 \%$ confluency, incubated with LysoTracker red for $4 \mathrm{~h}$, washed with PBS, and immediately photographed. (I) Myc-nick increases LC3BII and LC3AII without affecting ATGs. $(J-L)$ Myc-nick-expressing cells are sensitive to nutrient starvation in the presence of autophagy inhibitors. $(J, K)$ DLD1 cells $\left(5 \times 10^{5}\right)$ expressing vector and Myc-nick were seeded on $35-\mathrm{mm}$ dishes and counted after $2 \mathrm{~d}$. At that point, the medium was replaced with DMEM lacking glucose and glutamine in the absence

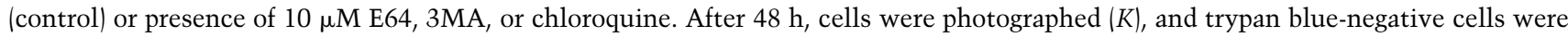
counted $(J) .(L)$ DLD1 cells expressing vector and Myc-nick were grown in the presence of autophagy inhibitors for $16 \mathrm{~h}$, fixed with paraformaldehyde, and immunostained for cleaved caspase 3. (M) Cells treated as in $L$ were processed for LC3B Western blot. (N) LC3Bpositive autophagosomes are proximal to acetylated microtubules in Myc-nick cells. (O) Myc-nick expression increases lysine acetylation of multiple cytoplasmic proteins. Confluent DLD1 cells expressing vector or Myc-nick were processed for acetylated lysine Western blot. $(P)$ ATG3 is acetylated in Myc-nick-expressing cells. Five milligrams of cytoplasmic lysates of DLD1 cells expressing vector or Myc-nick was immunoprecipitated with the anti-acetylated lysine antibody and immunoblotted for ATG3. (Q,R) Myc-nickinduced autophagy requires MBII. DLD1 cells expressing vector or Myc-nick were processed for LC3B and LC3A Western blot (Q) or for LC3B immunofluorescence after methanol fixation $(R)$. 
cells that survive chemotherapeutic drugs also accumulate the marker of DNA damage $\gamma \mathrm{H} 2 \mathrm{AX}$ (Supplemental Fig. S4I), suggesting that Myc-nick contributes to genomic instability and, potentially, increased cellular heterogeneity following chemotherapy.

\section{Myc-nick promotes autophagy}

Nutrient starvation and cellular stress are known to trigger high levels of autophagy, allowing damaged or excess proteins, lipids, and organelles to be recycled into cellular components essential for survival (Yang et al. 2011). The most commonly used markers of autophagy are the microtubule-associated proteins LC3I (LC3A, LC3B, and LC3C in humans), which, after partial cleavage and lipidation, generate LC3-II, which is internalized into autophagosomes (He and Klionsky 2009). We found that Myc-nick expression causes a dramatic increase in LC3B-II and LC3A-II in DLD1 cells without affecting the levels of the autophagy-inducing factors ATG3, ATG5, ATG7, and ATG12 (Fig. 6I). We also observed an increase in the number of lysosome-like vesicles labeled by LC3B (Fig. 6F), LC3A, and ATG3 (Fig. 6G), as determined by immunofluorescence of Myc-nick-expressing cells. Furthermore, in vivo labeling of Myc-nick-expressing cells using LysoTracker red demonstrates an increase in the number of acidic organelles (Fig. 6H). Interestingly, autophagy is known to be involved in tolerance of colon cancer cells to nutrient deprivation (Sato et al. 2007). Autophagy is known to confer resistance to chemotherapeutic agents by increasing the clearance of these drugs (Yang et al. 2011; Sui et al. 2013). Consistent with this idea, we found that treating colon cancer cells with etoposide caused an increase in the levels of LC3BII in both control and Mycnick-expressing cells (Supplemental Fig. S7D).

Treatment with autophagy inhibitors such as chloroquine, the protease inhibitor E64, and, to a lesser extent, 3-methyladenine (3MA) renders Myc-nick-expressing cells sensitive to apoptosis caused by glucose and glutamine deprivation (Fig. 6J,K) and increases cleaved caspase 3 (Fig. 6L). Blocking authophagy with E64 and chloroquine caused a marked increase in accumulation of LC3BII protein in Myc-nick-expressing cells compared with vectorexpressing cells (Fig. 6M). Note that 3MA and other PI3K inhibitors affected both control and Myc-nick cells similarly. This is consistent with Myc-nick acting downstream from PI3K, most likely on autophagic vesicle trafficking along acetylated microtubules in response to nutrient deprivation (Geeraert et al. 2010). Taken together, these results indicate that Myc-nick promotes autophagy that is at least in part responsible for the increased resistance to stress-induced apoptosis.

\section{Involvement of protein acetylation and the MBII region in Myc-nick-induced autophagy}

Recent studies have shown that increased lysine acetylation of several proteins, including $\alpha$-tubulin, salt-inducible kinase 2 (SIK2), HSP70, and ATG3, promotes autophagy under nutritional stress (Geeraert et al. 2010; Xie et al.
2010; Yi et al. 2012; Yang et al. 2013a,b). Because protein acetylation is proposed to play a positive role in activating autophagy, we analyzed the pattern of cytoplasmic proteins that are modified by lysine acetylation in Mycnick-expressing cells. We found that multiple cytoplasmic proteins are acetylated in the presence of Myc-nick in a MBII-dependent fashion (Fig. 6O; data not shown). Among those proteins, we identified ATG3 as one of the proteins acetylated in Myc-nick-expressing cells (Fig. 6P). Acetylation of yeast ATG3 is known to be transiently induced after starvation to promote binding to ATG8 and enhancement of autophagy (Yi et al. 2012). During nutrient deprivation, enhanced acetylation of $\alpha$-tubulin is required to induce autophagy (Geeraert et al. 2010), and acetylated microtubules are essential for fusion of autophagosomes with lysosomes (Xie et al. 2010). Consistent with these studies, we found that Myc-nick augments the levels of acetylated of $\alpha$-tubulin (Fig. 5F) and that LC3Bpositive vesicles are localized proximal to acetylated microtubules (Fig. 6N).

Because both protein acetylation and cell survival induced by Myc-nick are dependent on MBII, we asked whether autophagy also requires MBII. Deletion of MBII caused a reduction in the levels of LC3-BII and LC3A-II protein (Fig. 6Q) and prevented induction of autophagy, as measured by loss of LC3B-labeled autophagosomes (Fig. 6R).

\section{Myc-nick promotes fascin expression, filopodia formation, and cell motility}

We noted that the cohesive colonies generated by Mycnick-expressing cells (Supplemental Fig. S2D) exhibit intense membrane activity marked by the formation of filopodia, as visualized by actin staining (Fig. 7A). Filopodia are slender cellular protrusions involved in initiating cell-cell adhesion, sensing the environment, and guiding cell motility and, in cancer cells, are often an indication of increased metastatic potential (Machesky and Li 2010).

To explore the basis for the increased generation of filopodia, we examined the levels of several actin-associated proteins in Myc-nick-expressing cells. We found a dramatic increase in the expression of the actin-bundling protein fascin in Myc-nick-expressing cells (Fig. 7B). Fascin levels were induced in cells grown at high density (Fig. 7C) but not during nutrient deprivation (Fig. 7D) even though conversion of Myc into Myc-nick is stimulated under both conditions (Fig. 2F). Furthermore, we found that fascin down-regulation by siRNA was not sufficient to induce apoptosis in Myc-nick-expressing cells to the same extent as vector-expressing cells (Fig. 7E), indicating that fascin is probably not the major mediator of Myc-nick-induced cell survival. While there was no significant change in fascin half-life in Myc-nick-expressing cells (Fig. 7G), fascin mRNA was induced eightfold in Myc-nick-expressing cells and fourfold in cells expressing Myc-nick $\triangle$ MBII mutant as compared with vectorexpressing cells (Fig. $7 \mathrm{H})$. Consistent with reports that filopodia development is induced by fascin (Vignjevic et al. 2006; Aratyn et al. 2007; Zanet et al. 2012), we found 

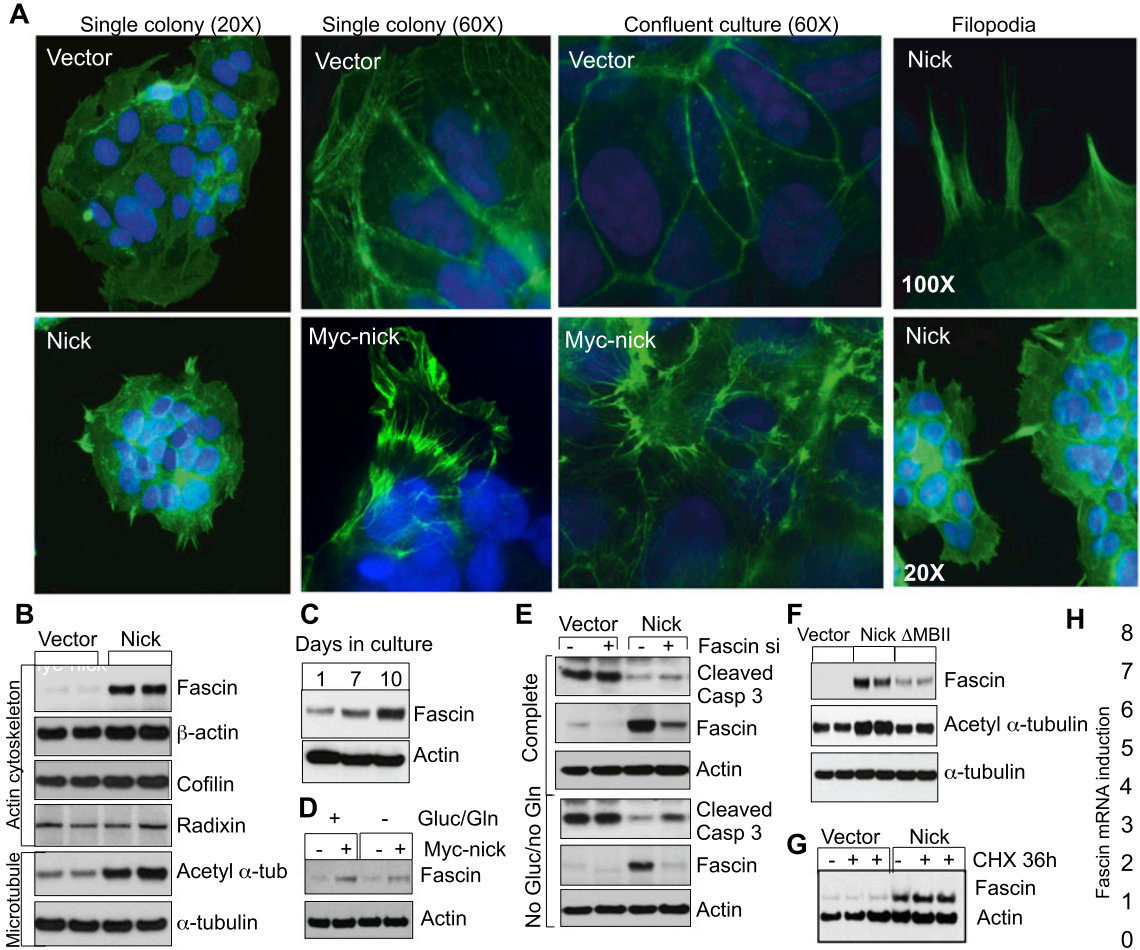

$\mathbf{F}_{\text {Vector Nick } \Delta \mathrm{MBI}}$
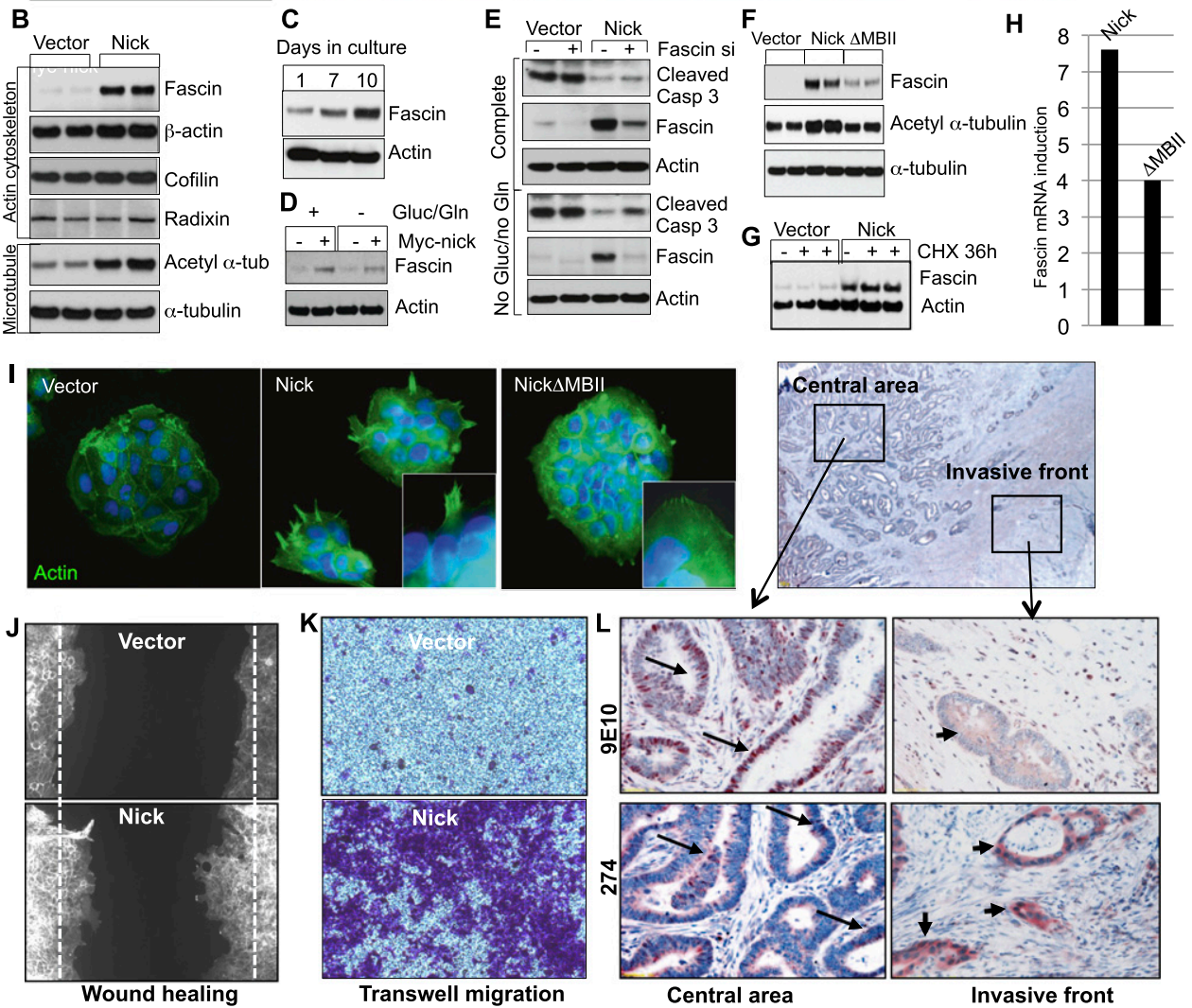

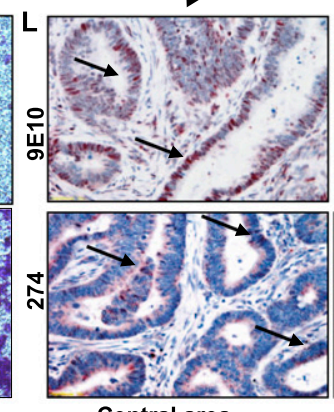

Central area

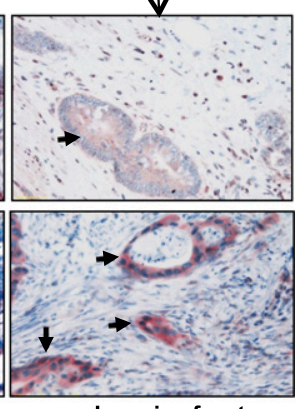

Invasive front

Figure 7. Myc-nick induces filopodia formation, enhances fascin expression, and promotes motility. (A) Myc-nick promotes an increase in actin-based cellular structures. DLD1 cells were grown as single colonies or confluent cultures and fixed with paraformaldehyde, and the actin cytoskeleton was stained with phalloidin. (B) Myc-nick induces fascin expression. Confluent DLD1 cells were processed for Western blot for the indicated components of the actin cytoskeleton. $(C)$ Fascin levels are elevated in confluent cultures. Cytoplasmic lysates used in Figure 2F were processed for fascin Western blot. $(D)$ Fascin levels are not significantly altered by glucose and glutamine deprivation. Confluent DLD1 cells were starved for glucose and glutamine for $24 \mathrm{~h}$. (E) DLD1 cells were transfected with fascin siRNA, and, $3 \mathrm{~d}$ later, the medium was replaced with complete medium or medium lacking glucose and glutamine for $24 \mathrm{~h}$. (F) Fascin induction by Myc-nick is dependent on MBII. (G) Myc-nick does not alter fascin protein stability. Confluent DLD1 cells were treated with cyclohexamide (CHX) for 36 h. $(H)$ Myc-nick expression promotes an increase in fascin mRNA. Confluent cultures of DLD1 cells expressing vector, Myc-nick, and Myc-nick $\triangle$ MBII were processed for fascin quantitative PCR. All values were normalized by actin mRNA and are represented as fold induction over vector-expressing cells. (I) Filopodia induction by Myc-nick is dependent on MBII. $(J, K)$ Myc-nick promotes cell motility. (J) Cells expressing vector or Myc-nick were grown to confluency, and a scratch was introduced in the monolayer. After $24 \mathrm{~h}$, cells were fixed in paraformaldehyde and stained with phalloidin. $(K)$ Cells $\left(5 \times 10^{3}\right)$ expressing vector or Myc-nick were placed on the top compartment of the $8-\mu \mathrm{m}$ transwell chamber. Cells that migrated across the filter were stained $24 \mathrm{~h}$ later using crystal violet. $(L)$ Myc staining is exclusively cytoplasmic in cells localized at the invasive front of tumors. The top picture displays a low-magnification view of a cross-section of a human colorectal carcinoma biopsy showing central and invasive areas of the tumor. The long arrows point to nuclear staining of Myc at the central area of the tumor, and the short arrows point to cytoplasmic staining for Myc at the invasive front. 
that the Myc-nick $\triangle$ MBII mutant is unable to induce mature filopodia when expressed in DLD1 cells (Fig. 7F,I).

Several studies have established that fascin is upregulated in cancer cells, where it drives epithelial-tomesenchymal progression, conferring motility and invasive properties to cancer cells (Li et al. 2010; Machesky and Li 2010). To address the association of Myc-nick with cell motility, we carried out both a wound healing assay on confluent cultures of DLD1 cells and a migration assay using a transwell migration chamber. In both experiments, Myc-nick-expressing cells exhibited a higher degree of motility than control cells (Fig. 7J,K).

Immunohistochemistry studies revealed fascin to be highly expressed at the invasive front of human colorectal cancer (Vignjevic et al. 2007; Ozerhan et al. 2010). To investigate the association of Myc-nick with metastatic behavior, we compared the localization of Myc in the central area of human colorectal tumor biopsies and the invasive front of the same tumors by immunohistochemistry. In nearly $50 \%$ of the tumors analyzed (nine out of 19 cases, 47\%), we detected cytoplasmic Myc signal with both $\mathrm{N}$-terminal and C-terminal antibodies in the invasive regions of the tumor (Fig. 7L; Supplemental Table S1). As shown in Figure 2, A-I, such a signal in colon cancer cells invariably indicates the presence of Myc-nick and, frequently, full-length Myc retained in the cytoplasm prior to cleavage. These data suggest that the invasive fronts of tumors are regions where processing of fulllength Myc to Myc-nick is occurring, possibly to promote survival and subsequent metastasis.

\section{Discussion}

Calpain-mediated cleavage of Myc abrogates stressinduced cell death in tumors with activated Myc

Cancer progression is restricted by a disorganized tumor vasculature that limits the delivery of nutrients and oxygen (Tredan et al. 2007). Tumor cells located distal to blood vessels may become hypoxic and nutrient-deprived. While such cells may remain viable, they proliferate slowly and more readily achieve resistance to chemotherapeutic agents, thereby permitting survival and repopulation (Saggar et al. 2013). This is consistent with reports that tumor hypoxia is associated with poor clinical outcome (Hockel et al. 1996; Jubb et al. 2009). Many tumors exhibit deregulated Myc activity that augments growth and proliferation, which in turn requires increased amounts of carbon sources such as glucose and glutamine in order to meet the needs of reprogrammed anabolic metabolism (Dang 2010, 2012; Sloan and Ayer 2010; Vander Heiden et al. 2010). Indeed, withdrawal of glucose and glutamine from Myc transformed cells causes a dramatic induction of cell death in vitro (Shim et al. 1998; Yuneva et al. 2007). Since Myc induces death under conditions of nutrient and oxygen deprivation (Evan et al. 1992; Shortt and Johnstone 2012; Wong et al. 2013), it is likely that poorly vascularized areas of tumors evolve mechanisms for evasion of Myc-induced apoptosis. Here we show that one such mechanism involves the down-regulation of Myc protein by calpain-mediated proteolysis as a rapid response to altered levels of nutrients and oxygen. Other studies have demonstrated that Myc degradation is accelerated under hypoxia as a means of blocking the cell death pathway (Li et al. 2009; Wong et al. 2013). We found that preventing Myc cleavage with calpain inhibitors or by overexpressing a cleavage-deficient mutant of Myc (Myc $\Delta 298-311)$ causes increased cell death in colon cancer cells (Fig. 4), supporting the idea that the cleavage of Myc by calpains prevents apoptosis. This finding is consistent with a report that calpain inhibitors increase tumor cell death in the $\mathrm{E} \mu$-Myc mouse model of lymphoma (Li et al. 2012). Taken together, these studies argue that preventing Myc cleavage may provide a means of stimulating cell death of Myc-dependent tumors.

\section{An active role for Myc-nick in promoting survival in response to stress}

In principle, simply decreasing the levels of Myc protein in tumor cells through complete proteolytic degradation might be sufficient to permit survival under conditions of stress (Wong et al. 2013). Our data, however, suggest another level of complexity, in that calpain-mediated proteolytic cleavage at Lys298 in Myc not only reduces the amount of full-length Myc but also produces Mycnick, a cytoplasmic protein possessing a unique activity that contributes to cell survival. We reported previously that Myc-nick is generated in normal cells at high density and during terminal differentiation (Conacci-Sorrell et al. 2010). Here we show that diverse tumor types have high levels of both full-length Myc and Myc-nick and that Myc-nick is produced as a response to hypoxia as well as to glucose withdrawal (Figs. 1,2). Immunohistochemistry of human colon cancer biopsies demonstrates both separate and overlapping tumor regions exhibiting high levels of nuclear or cytoplasmic Myc possessing the antigenic characteristics of Myc and Myc-nick, respectively (Fig. $1 \mathrm{~J}, \mathrm{~K})$. We attribute this heterogeneity in Myc and Mycnick expression to differences in the microenvironment within the tumor.

To test the idea that Myc-nick has a physiological function, we overexpressed it in colon cancer cells and found that it delayed death induced by a lack of nutrients, growth factors, or chemotherapeutic agents (Figs. 3-6). Under these conditions, Myc-nick did not permanently inhibit cell death but significantly delayed death for a period of several days. Myc-nick expression also augmented anchorage-independent growth of colon cancer cells in soft agar by increasing survival of cells removed from the substratum (Fig. 3F). Importantly, Myc-nick prevented cell death induced by ectopic expression of a mutant form of Myc resistant to calpain cleavage (Fig. 4), further supporting the hypothesis that Myc-nick plays an active role in attenuating cell death. We reported previously that Myc-nick accelerated the differentiation of committed myoblasts in low or no serum (ConacciSorrell et al. 2010). However, we now consider this effect to be a consequence of increased survival of myoblasts 
under conditions of stress due to serum deprivation during differentiation.

\section{Myc-nick increases resistance of cancer cells to chemotherapy}

A potentially important implication of Myc-nick's capacity to attenuate apoptosis relates to its ability to prolong tumor cell survival following treatment with drugs commonly used as chemotherapeutic agents, such as etoposide, cisplatin, oxaliplatin, and imatinib (Fig. 6A). While these drugs alone do not appear to induce Myc-nick, we surmise that under conditions of restricted oxygen and nutrient uptake within tumors, Myc-nick is induced and acts to protect tumor cells following drug treatment. Because anti-cancer drugs reach the target tumor cells through the vasculature, the same cells that receive low levels of $\mathrm{O}_{2}$ and nutrients and generate Myc-nick are also exposed to lower drug concentrations. Such cells would also be expected to have relatively low rates of proliferation and altered metabolism, further permitting evasion of drug toxicity.

\section{Myc-nick and autophagy}

Our data indicate that expression of Myc-nick promotes the formation of mature autophagosomes (Fig. $6 \mathrm{~F}-\mathrm{H}$ ). Autophagy is an important mediator of cell survival, responsible for recycling macromolecules to provide essential precursors under nutrient restriction and stress conditions (Yang et al. 2011) occurring as a consequence of poor vascularization (Sato et al. 2007). Because inhibition of Myc-nick-stimulated autophagy results in increased apoptosis, we presume that autophagy is a major factor in facilitating the survival of colon cancer cells expressing Myc-nick. Furthermore, autophagy has also being implicated in conferring drug resistance to cancer cells by increasing the rate of drug clearance via the lysosome system (Yang et al. 2011; Sui et al. 2013). Thus, the tolerance to chemotherapeutic agents elicited by Myc-nick (Fig. 6A) may also result from increased autophagy and lysosome formation (Supplemental Fig. S7D). Therefore, we propose that activation of autophagy is the major mechanism by which Myc-nick promotes cell survival under adverse conditions. While the involvement of Myc as well as factors associated with Myc in autophagy has been demonstrated in several studies and has been proposed to contribute to tumorigenicity (Dey et al. 2013; Nagy et al. 2013; Toh et al. 2013; Wolf et al. 2013), our studies suggest that induction of autophagy by Myc is mediated at least in part by its by-product, Myc-nick.

\section{Myc-nick and protein lysine acetylation}

The highly conserved MBII sequence located within the $\mathrm{N}$-terminal region of full-length Myc recruits a coactivator complex and HATs to Myc-Max DNA-binding sites. Myc-nick, although a cytoplasmic protein, contains MBII, associates with acetyltransferases, and promotes acetylation of $\alpha$-tubulin in fibroblasts, myoblasts (Conacci-Sorrell et al. 2010), and colon cancer cells (Fig. 3H,I). This requires MBII, as does the ability of Myc-nick to augment autophagy and cell survival in response to stress. Under nutritional stress, protein lysine acetylation was found to activate several factors involved in autophagy, including SIK2, HSP70, ATG3, and $\alpha$-tubulin (Geeraert et al. 2010; Yi et al. 2012; Yang et al. 2013a,b). Previous studies have found that acetylated $\alpha$-tubulin is required for the migration of autophagosomes and their subsequent fusion with lysosomes (Geeraert et al. 2010; Xie et al. 2010).

We found that Myc-nick augments acetylation of multiple cytoplasmic proteins, including ATG3 (Fig. 6O,P), and earlier identified $\alpha$-tubulin to be one of the major targets of Myc-nick in the cytoplasm (Figs. 5F, 7F; Conacci-Sorrell et al. 2010). Because Myc-nick-induced protein acetylation and cell survival both require the MBII region, we propose that the mechanism by which Myc-nick induces cell survival is by promoting lysine acetylation of $\alpha$-tubulin and ATG3. It is also likely that other, as yet unidentified cytoplasmic proteins acetylated by Myc-nick cooperate to increase autophagy and cell survival under stress. Furthermore, acetyltransferases appear to associate with Myc-nick independent of MBII binding (Conacci-Sorrell et al. 2010), possibly accounting for the residual activity of the Myc-nick $\triangle \mathrm{MBII}$ mutant (Figs. 6Q, 7F,H).

\section{A potential role for Myc-nick in metastasis}

We found that overexpressing Myc-nick not only promoted the survival of colon cancer cells but also accelerated their motility, as measured by transwell migration and wound healing assays (Fig. 7J,K). In agreement with the idea that Myc-nick promotes cell motility, we found enrichment for a cytoplasmic Myc signal in cells localized at the invasive front of about half of the human colorectal tumors examined (Fig. 7L). This indicates retention of full-length Myc in the cytoplasm, which invariably results in cleavage and generation of Myc-nick, as we observed with cultured colon cancer cells under hypoxia (e.g., see Fig. 2).

The invasive front of colorectal cancers was earlier shown to contain nonproliferative/arrested cells that are undergoing epithelial-to-mesenchymal transition (EMT), presumably leading to metastasis at distal sites (Brabletz et al. 2001; Jung et al. 2001). Importantly, stress and hypoxia, conditions that augment the production of Mycnick, were shown to promote colon cancer invasion by inducing an EMT (Kahlert et al. 2011; Hongo et al. 2013). In searching for mechanisms by which Myc-nick promotes migration of colon cancer cells, we found that Myc-nick induces the expression of the actin-bundling protein fascin. Multiple studies have demonstrated that fascin is dramatically up-regulated in cancer cells, where it drives migration (Li et al. 2010; Machesky and Li 2010). Furthermore, immunohistochemistry studies found fascin to be highly expressed at the invasive front of human colorectal cancers, establishing fascin as a robust marker of invasiveness (Vignjevic et al. 2007; Ozerhan et al. 2010). Myc-nick expression results in sharply increased levels of 
fascin, elevated numbers of filopodia, and augmented motility and therefore is likely to contribute to the invasiveness of Myc-dependent tumors (Machesky and Li 2010).

Tubulin acetylation may also be linked to the changes in cell adhesion and migration promoted by Myc-nick. Communication between microtubules and the actin cytoskeleton is widespread and known to be essential for processes such as migration, cell polarity, and division (Goode et al. 2000; Kodama et al. 2004). Microtubules have been shown to target filopodia and regulate their movement and density (Schober et al. 2007). Alterations within the microtubule cytoskeleton, such as the acetylation of $\alpha$-tubulin, may provoke altered transcriptional programs, resulting in expression of fascin, and may thereby underlie modifications of the actin cytoskeleton and changes in cell-cell adhesion and motility. Once believed to be restricted to histones and tubulin, protein lysine acetylation has recently emerged as an important post-translational modification regulating the functions of many proteins (Barcellos et al. 2013; Xu et al. 2013). Therefore, identifying and characterizing proteins that are acetylated by Myc-nick may lead to delineation of critical cytoplasmic effectors of deregulated Myc in cancer cells.

\section{Materials and methods}

\section{Cell lines and mouse tissues}

Cell lines were maintained in DMEM with $4.5 \mathrm{~g}$ of glucose, $10 \%$ FCS, and $100 \mathrm{U} / \mathrm{mL}$ penicillin/streptomycin. FHS74 human small intestinal cells were cultured in Hybri-Care medium American Type Culture Collection 46-X supplemented with 30 $\mathrm{ng} / \mathrm{mL}$ EGF and $10 \%$ FCS.

For starvation experiments, cells were grown to confluency, and growth medium was replaced for DMEM lacking nutrients. For experiments involving hypoxia, cells were grown to confluency, the growth medium was replaced, and plates were either placed in a $21 \% \mathrm{O}_{2}$ or $1 \% \mathrm{O}_{2}$ incubator. For cyclohexamide (CHX) chase experiments, cells were cultured to confluency, and the culture medium was replaced $24 \mathrm{~h}$ before lysis. CHX $(50 \mu \mathrm{g} / \mathrm{mL})$ in combination with $50 \mu \mathrm{M}$ calpain inhibitor XII was added to cells for the indicated time points.

In vitro cleavage of Myc, immunofluorescence, and retroviral infections were performed as described by Conacci-Sorrell et al. (2010). For overexpression experiments in 293T cells, Fugene (Roche) transfected cells were harvested $3 \mathrm{~d}$ after transfection, with a change in culture medium $24 \mathrm{~h}$ before harvesting.

\section{Growth in soft agar}

Growth in soft agar was performed as previously described (Rodriguez Fernandez et al. 1993), with adaptations. Cells (15 $\times$ $10^{3}$ ) were resuspended in DMEM containing $0.3 \%$ bacto-agar and $10 \%$ FCS and were plated in $35-\mathrm{mm}$ plates containing a bottom layer of solidified DMEM, $10 \%$ FCS, and $0.8 \%$ bacto-agar. Plates were incubated at either $21 \% \mathrm{O}_{2}$ or $1 \% \mathrm{O}_{2}$ for $2-3 \mathrm{wk}$.

\section{Migration assay}

Transwell migration experiments were performed according to the manufacturer's instructions for Corning $8-\mu \mathrm{m}$ chambers.
Briefly, $5 \times 10^{3}$ cells were placed in the upper compartment of a transwell chamber, with both chambers containing medium. Twenty-four hours later, the cells remaining in the upper compartment were removed using cotton swabs, while the cells that crossed the membrane were fixed and stained using crystal violet in methanol.

\section{Protein lysates}

Normal and tumor mouse tissues were snap-frozen upon dissection, and total extracts were prepared in RIPA buffer by sonication. For total extracts, cells were lysed in RIPA buffer, and for cellular fractionation, samples were prepared as described by Conacci-Sorrell et al. (2010).

For villi and crypt preparation, small intestines were opened, washed, cut into 5-mm sections, placed in ice-cold PBS + $5 \mathrm{mM}$ EDTA, and pipetted vigorously. The supernatant after filtration and centrifugation contained the villi, while the pellet contained the crypts.

\section{Immunohistochemistry}

Sections $(4 \mathrm{~mm})$ were deparaffinized, rehydrated, and pretreated for $10 \mathrm{~min}$ in a microwave (or in a pressure cooker) in Dako buffer $(\mathrm{pH} 6)$. They were then incubated overnight at $4^{\circ} \mathrm{C}$, with the primary antibodies diluted in RPMI $1640+10 \%$ bovine serum (9E10 at $1: 175 ; 274$ at 1:4). Slides were washed twice with TBS/ $0.1 \%$ Tween 20 and developed with the EnVision System (Dako) and AEC for visualization according to the manufacturer's instructions.

\section{Pharmacological inhibitors, antibodies, recombinant proteins, siRNAs, and constructs}

The pharmacological inhibitors from EMD were $200 \mu \mathrm{M}$ epoxomycin, $40 \mathrm{nM}$ MG132, $25 \mu \mathrm{M}$ leptomycin B, $50 \mu \mathrm{M}$ calpain inhibitor XII, $50 \mu \mathrm{M}$ calpain inhibitor VI, and $50 \mu \mathrm{M}$ calpeptin. The chemicals from Sigma-Aldrich were etoposide, imatinib, cisplatin, and oxaliplatin.

Antibodies against c-Myc (9E10) Sin3, Max, p53, p21, fascin, and radixin were from Santa Cruz Biotechnology. Anti-tubulin $(\alpha, \beta$, and acetylated) and actin were from Sigma. Anti-Myc 274 and 143 were gifts from N. Ikegaki (University of Illinois). Anticleaved caspase 3, acetylated lysine, P-T58 Myc, MCL1, LC3A, LC3B, ATG3, ATG5, ATG7, and ATG12 were from Cell Signaling, and anti-P $\gamma \mathrm{H} 2 \mathrm{AX}$ and cofilin were from Abcam.

The constructs used were as follows: Myc and Myc-nick were cloned by PCR into BamHI and EcoRI sites of pBabe puro and pBabe hygro and used to prepare retrovirus. Myc and Myc-nick constructs used for transient transfections in 293T cells were cloned into pCS2 ${ }^{+}$vector. Fascin, GCN5, Tip60, and TRRAP siRNAs were from Santa Cruz Biotechnology.

The primers used for fascin quantitative PCR were $5^{\prime}$-TCCA CGCGCCAGGGTATGGAC-3' and 5' ${ }^{\prime}$-ACTTGCCCGTGTGG GTACGG-3'.

\section{Acknowledgments}

We are grateful to Nao Ikegaki, William Tansey, John Sedivy, Jonathan Grim, Bruce Clurman, Markus Welker, Lukas Low, Brian Freie, and Denise Galloway for advice, protocols, reagents, and equipment essential for this work. We also thank James Olson for mouse medulloblastoma samples, and Peter Nelson for prostate cancer xenografts. This work was supported by National Institutes of Health/National Cancer Institute grant CA20525 (to R.N.E.). 


\section{References}

Adams JM, Cory S. 1985. Myc oncogene activation in B and T lymphoid tumours. Proc $R$ Soc Lond B Biol Sci 226: 59-72.

Aratyn YS, Schaus TE, Taylor EW, Borisy GG. 2007. Intrinsic dynamic behavior of fascin in filopodia. Mol Biol Cell 18: 3928-3940.

Bai MK, Costopoulos JS, Christoforidou BP, Papadimitriou CS. 1994. Immunohistochemical detection of the c-myc oncogene product in normal, hyperplastic and carcinomatous endometrium. Oncology 51: 314-319.

Barcellos KS, Bigarella CL, Wagner MV, Vieira KP, Lazarini M, Langford PR, Machado-Neto JA, Call SG, Staley DM, Chung JY, et al. 2013. ARHGAP21 protein, a new partner of $\alpha$-tubulin involved in cell-cell adhesion formation and essential for epithelial-mesenchymal transition. J Biol Chem 288: 21792189.

Brabletz T, Jung A, Reu S, Porzner M, Hlubek F, Kunz-Schughart LA, Knuechel R, Kirchner T. 2001. Variable $\beta$-catenin expression in colorectal cancers indicates tumor progression driven by the tumor environment. Proc Natl Acad Sci 98: 10356-10361.

Calcagno DQ, Guimaraes AC, Leal MF, Seabra AD, Khayat AS, Pontes TB, Assumpcao PP, De Arruda Cardoso Smith M, Burbano RR. 2009. MYC insertions in diffuse-type gastric adenocarcinoma. Anticancer Res 29: 2479-2483.

Conacci-Sorrell M, Eisenman RN. 2011. Post-translational control of Myc function during differentiation. Cell Cycle 10: 604-610.

Conacci-Sorrell M, Ngouenet C, Eisenman RN. 2010. Myc-nick: a cytoplasmic cleavage product of Myc that promotes $\alpha$-tubulin acetylation and cell differentiation. Cell 142: 480-493.

Dalerba P, Dylla SJ, Park IK, Liu R, Wang X, Cho RW, Hoey T, Gurney A, Huang EH, Simeone DM, et al. 2007. Phenotypic characterization of human colorectal cancer stem cells. Proc Natl Acad Sci 104: 10158-10163.

Dang CV. 2010. Glutaminolysis: supplying carbon or nitrogen or both for cancer cells? Cell Cycle 9: 3884-3886.

Dang CV. 2011. Enigmatic MYC conducts an unfolding systems biology symphony. Genes Cancer 1: 526-531.

Dang CV. 2012. MYC on the path to cancer. Cell 149: 22-35.

Dang CV. 2013. MYC, metabolism, cell growth, and tumorigenesis. Cold Spring Harb Perspect Med 3: a014217.

Dey S, Tameire F, Koumenis C. 2013. PERK-ing up autophagy during MYC-induced tumorigenesis. Autophagy 9: 612614.

Eilers M, Eisenman RN. 2008. Myc's broad reach. Genes Dev 22: 2755-2766.

Evan GI, Wyllie AH, Gilbert CS, Littlewood TD, Land H, Brooks M, Waters CM, Penn LZ, Hancock DC. 1992. Induction of apoptosis in fibroblasts by c-myc protein. Cell 69: 119-128.

Frank SR, Parisi T, Taubert S, Fernandez P, Fuchs M, Chan HM, Livingston DM, Amati B. 2003. MYC recruits the TIP60 histone acetyltransferase complex to chromatin. EMBO Rep 4: $575-580$.

Freedman VH, Shin SI. 1974. Cellular tumorigenicity in nude mice: correlation with cell growth in semi-solid medium. Cell 3: 355-359.

Geeraert C, Ratier A, Pfisterer SG, Perdiz D, Cantaloube I, Rouault A, Pattingre S, Proikas-Cezanne T, Codogno P, Pous C. 2010. Starvation-induced hyperacetylation of tubulin is required for the stimulation of autophagy by nutrient deprivation. J Biol Chem 285: 24184-24194.
Goode BL, Drubin DG, Barnes G. 2000. Functional cooperation between the microtubule and actin cytoskeletons. Curr Opin Cell Biol 12: 63-71.

Guccione E, Martinato F, Finocchiaro G, Luzi L, Tizzoni L, Dall'Olio V, Zardo G, Nervi C, Bernard L, Amati B. 2006. Myc-binding-site recognition in the human genome is determined by chromatin context. Nat Cell Biol 8: 764770 .

Hanahan D, Weinberg RA. 2011. Hallmarks of cancer: the next generation. Cell 144: 646-674.

Hatton BA, Knoepfler PS, Kenney AM, Rowitch DH, de Alboran IM, Olson JM, Eisenman RN. 2006. N-myc is an essential downstream effector of Shh signaling during both normal and neoplastic cerebellar growth. Cancer Res 66: 8655-8661.

He C, Klionsky DJ. 2009. Regulation mechanisms and signaling pathways of autophagy. Annu Rev Genet 43: 67-93.

He TC, Sparks AB, Rago C, Hermeking H, Zawel L, da Costa LT, Morin PJ, Vogelstein B, Kinzler KW. 1998. Identification of c-MYC as a target of the APC pathway. Science 281: 15091512.

Hermeking H, Funk JO, Reichert M, Ellwart JW, Eick D. 1995. Abrogation of p53-induced cell cycle arrest by c-Myc: evidence for an inhibitor of p21WAF1/CIP1/SDI1. Oncogene 11: 1409-1415.

Hockel M, Schlenger K, Aral B, Mitze M, Schaffer U, Vaupel P. 1996. Association between tumor hypoxia and malignant progression in advanced cancer of the uterine cervix. Cancer Res 56: 4509-4515.

Hongo K, Tsuno NH, Kawai K, Sasaki K, Kaneko M, Hiyoshi M, Murono K, Tada N, Nirei T, Sunami E, et al. 2013. Hypoxia enhances colon cancer migration and invasion through promotion of epithelial-mesenchymal transition. I Surg Res 182: $75-84$.

Ji H, Wu G, Zhan X, Nolan A, Koh C, De Marzo A, Doan HM, Fan J, Cheadle C, Fallahi M, et al. 2011. Cell-type independent MYC target genes reveal a primordial signature involved in biomass accumulation. PLOS ONE 6: e26057.

Jubb AM, Buffa FM, Harris AL. 2009. Assessment of tumour hypoxia for prediction of response to therapy and cancer prognosis. J Cell Mol Med 14: 18-29.

Jung A, Schrauder M, Oswald U, Knoll C, Sellberg P, Palmqvist R, Niedobitek G, Brabletz T, Kirchner T. 2001. The invasion front of human colorectal adenocarcinomas shows colocalization of nuclear $\beta$-catenin, cyclin D1, and p16INK4A and is a region of low proliferation. Am J Pathol 159: 16131617.

Kahlert C, Lahes S, Radhakrishnan P, Dutta S, Mogler C, Herpel E, Brand K, Steinert G, Schneider M, Mollenhauer M, et al. 2011. Overexpression of ZEB2 at the invasion front of colorectal cancer is an independent prognostic marker and regulates tumor invasion in vitro. Clin Cancer Res 17: 76547663.

Keith B, Johnson RS, Simon MC. 2011. HIF $1 \alpha$ and HIF2 $\alpha$ : sibling rivalry in hypoxic tumour growth and progression. Nat Rev Cancer 12: 9-22.

Kim JW, Zeller KI, Wang Y, Jegga AG, Aronow BJ, O’Donnell KA, Dang CV. 2004. Evaluation of myc E-box phylogenetic footprints in glycolytic genes by chromatin immunoprecipitation assays. Mol Cell Biol 24: 5923-5936.

Knoepfler PS, Zhang XY, Cheng PF, Gafken PR, McMahon SB, Eisenman RN. 2006. Myc influences global chromatin structure. EMBO J 25: 2723-2734.

Kodama A, Lechler T, Fuchs E. 2004. Coordinating cytoskeletal tracks to polarize cellular movements. I Cell Biol 167: 203-207. 
Li Q, Kluz T, Sun H, Costa M. 2009. Mechanisms of c-myc degradation by nickel compounds and hypoxia. PLOS ONE 4: e8531.

Li A, Dawson JC, Forero-Vargas M, Spence HJ, Yu X, Konig I, Anderson K, Machesky LM. 2010. The actin-bundling protein fascin stabilizes actin in invadopodia and potentiates protrusive invasion. Curr Biol 20: 339-345.

Li H, Nepal RM, Martin A, Berger SA. 2012. Induction of apoptosis in Emu-myc lymphoma cells in vitro and in vivo through calpain inhibition. Exp Hematol 40: 548-563.e2.

Machesky LM, Li A. 2010. Fascin: invasive filopodia promoting metastasis. Commun Integr Biol 3: 263-270.

McMahon SB, Wood MA, Cole MD. 2000. The essential cofactor TRRAP recruits the histone acetyltransferase hGCN5 to c-Myc. Mol Cell Biol 20: 556-562.

Mucaj V, Shay JE, Simon MC. 2012. Effects of hypoxia and HIFs on cancer metabolism. Int J Hematol 95: 464-470.

Nagy P, Varga A, Pircs K, Hegedus K, Juhasz G. 2013. Myc-driven overgrowth requires unfolded protein response-mediated induction of autophagy and antioxidant responses in Drosophila melanogaster. PLoS Genet 9: e1003664.

Nie Z, Hu G, Wei G, Cui K, Yamane A, Resch W, Wang R, Green DR, Tessarollo L, Casellas R, et al. 2012. c-Myc is a universal amplifier of expressed genes in lymphocytes and embryonic stem cells. Cell 151: 68-79.

Orian A, van Steensel B, Delrow J, Bussemaker HJ, Li L, Sawado T, Williams E, Loo LW, Cowley SM, Yost C, et al. 2003. Genomic binding by the Drosophila Myc, Max, Mad/Mnt transcription factor network. Genes Dev 17: 1101-1114.

Ozerhan IH, Ersoz N, Onguru O, Ozturk M, Kurt B, Cetiner S. 2010. Fascin expression in colorectal carcinomas. Clinics 65: 157-164.

Pietilainen T, Lipponen P, Aaltomaa S, Eskelinen M, Kosma VM, Syrjanen K. 1995. Expression of c-myc proteins in breast cancer as related to established prognostic factors and survival. Anticancer Res 15: 959-964.

Rahl PB, Lin CY, Seila AC, Flynn RA, McCuine S, Burge CB, Sharp PA, Young RA. 2010. c-Myc regulates transcriptional pause release. Cell 141: 432-445.

Ricci-Vitiani L, Lombardi DG, Pilozzi E, Biffoni M, Todaro M, Peschle C, De Maria R. 2007. Identification and expansion of human colon-cancer-initiating cells. Nature 445: 111115.

Rodriguez Fernandez JL, Geiger B, Salomon D, Ben-Ze'ev A. 1993. Suppression of vinculin expression by antisense transfection confers changes in cell morphology, motility, and anchorage-dependent growth of 3T3 cells. I Cell Biol 122: 1285-1294.

Ruzinova MB, Caron T, Rodig SJ. 2010. Altered subcellular localization of c-Myc protein identifies aggressive B-cell lymphomas harboring a c-MYC translocation. Am I Surg Pathol 34: 882-891.

Saggar JK, Yu M, Tan Q, Tannock IF. 2013. The tumor microenvironment and strategies to improve drug distribution. Front Oncol 3: 154.

Sansom OJ, Meniel VS, Muncan V, Phesse TJ, Wilkins JA, Reed KR, Vass JK, Athineos D, Clevers H, Clarke AR. 2007. Myc deletion rescues Apc deficiency in the small intestine. Nature 446: 676-679.

Sato K, Tsuchihara K, Fujii S, Sugiyama M, Goya T, Atomi Y, Ueno T, Ochiai A, Esumi H. 2007. Autophagy is activated in colorectal cancer cells and contributes to the tolerance to nutrient deprivation. Cancer Res 67: 9677-9684.

Schober JM, Komarova YA, Chaga OY, Akhmanova A, Borisy GG. 2007. Microtubule-targeting-dependent reorganization of filopodia. J Cell Sci 120: 1235-1244.
Shim H, Dolde C, Lewis BC, Wu CS, Dang G, Jungmann RA, Dalla-Favera R, Dang CV. 1997. c-Myc transactivation of LDH-A: implications for tumor metabolism and growth. Proc Natl Acad Sci 94: 6658-6663.

Shim H, Chun YS, Lewis BC, Dang CV. 1998. A unique glucosedependent apoptotic pathway induced by c-Myc. Proc Natl Acad Sci 95: 1511-1516.

Shortt J, Johnstone RW. 2012. Oncogenes in cell survival and cell death. Cold Spring Harb Perspect Biol4: a009829.

Sloan EJ, Ayer DE. 2010. Myc, mondo, and metabolism. Genes Cancer 1: 587-596.

Storr SJ, Carragher NO, Frame MC, Parr T, Martin SG. 2011. The calpain system and cancer. Nat Rev Cancer 11: 364374.

Sui X, Chen R, Wang Z, Huang Z, Kong N, Zhang M, Han W, Lou F, Yang J, Zhang Q, et al. 2013. Autophagy and chemotherapy resistance: a promising therapeutic target for cancer treatment. Cell Death Dis 4: e838.

Toh PP, Luo S, Menzies FM, Rasko T, Wanker EE, Rubinsztein DC. 2013. Myc inhibition impairs autophagosome formation. Hum Mol Genet 22: 5237-5248.

Tredan O, Galmarini CM, Patel K, Tannock IF. 2007. Drug resistance and the solid tumor microenvironment. I Natl Cancer Inst 99: 1441-1454.

Vander Heiden MG, Locasale JW, Swanson KD, Sharfi H, Heffron GJ, Amador-Noguez D, Christofk HR, Wagner G, Rabinowitz JD, Asara JM, et al. 2010. Evidence for an alternative glycolytic pathway in rapidly proliferating cells. Science 329: 1492-1499.

Vignjevic D, Kojima S, Aratyn Y, Danciu O, Svitkina T, Borisy GG. 2006. Role of fascin in filopodial protrusion. J Cell Biol 174: $863-875$.

Vignjevic D, Schoumacher M, Gavert N, Janssen KP, Jih G, Lae M, Louvard D, Ben-Ze'ev A, Robine S. 2007. Fascin, a novel target of $\beta$-catenin-TCF signaling, is expressed at the invasive front of human colon cancer. Cancer Res 67: 68446853.

Vinci M, Gowan S, Boxall F, Patterson L, Zimmermann $M$, Court W, Lomas C, Mendiola M, Hardisson D, Eccles SA. 2011. Advances in establishment and analysis of three-dimensional tumor spheroid-based functional assays for target validation and drug evaluation. BMC Biol 10: 29 .

Wagner AJ, Kokontis JM, Hay N. 1994. Myc-mediated apoptosis requires wild-type p53 in a manner independent of cell cycle arrest and the ability of p53 to induce p21waf1/cip1. Genes Dev 8: 2817-2830.

Wolf E, Gebhardt A, Kawauchi D, Walz S, von Eyss B, Wagner N, Renninger C, Krohne G, Asan E, Roussel MF et al. 2013. Mizl is required to maintain autophagic flux. Nat Commun 4: 2535.

Wong WJ, Qiu B, Nakazawa MS, Qing G, Simon MC. 2013. MYC degradation under low O2 tension promotes survival by evading hypoxia-induced cell death. Mol Cell Biol 33: 3494-3504.

Xie R, Nguyen S, McKeehan WL, Liu L. 2010. Acetylated microtubules are required for fusion of autophagosomes with lysosomes. BMC Cell Biol 11: 89.

Xu W, Li Y, Liu C, Zhao S. 2013. Protein lysine acetylation guards metabolic homeostasis to fight against cancer. Oncogene. doi: 10.10388/onc.2013.163.

Yang ZJ, Chee CE, Huang S, Sinicrope FA. 2011. The role of autophagy in cancer: therapeutic implications. Mol Cancer Ther 10: 1533-1541.

Yang FC, Tan BC, Chen WH, Lin YH, Huang JY, Chang HY, Sun HY, Hsu PH, Liou GG, Shen J, et al. 2013a. Reversible 
acetylation regulates salt-inducible kinase (SIK2) and its function in autophagy. J Biol Chem 288: 6227-6237.

Yang Y, Fiskus W, Yong B, Atadja P, Takahashi Y, Pandita TK, Wang HG, Bhalla KN. 2013b. Acetylated hsp70 and KAP1mediated Vps34 SUMOylation is required for autophagosome creation in autophagy. Proc Natl Acad Sci 110: 68416846.

Yi C, Ma M, Ran L, Zheng J, Tong J, Zhu J, Ma C, Sun Y, Zhang S, Feng W, et al. 2012. Function and molecular mechanism of acetylation in autophagy regulation. Science 336: 474-477.

Yuneva M, Zamboni N, Oefner P, Sachidanandam R, Lazebnik Y. 2007. Deficiency in glutamine but not glucose induces MYC-dependent apoptosis in human cells. J Cell Biol 178: 93-105.

Zanet J, Jayo A, Plaza S, Millard T, Parsons M, Stramer B. 2012. Fascin promotes filopodia formation independent of its role in actin bundling. J Cell Biol 197: 477-486.

Zindy F, Eischen CM, Randle DH, Kamijo T, Cleveland JL, Sherr CJ, Roussel MF. 1998. Myc signaling via the ARF tumor suppressor regulates p53-dependent apoptosis and immortalization. Genes Dev 12: 2424-2433. 


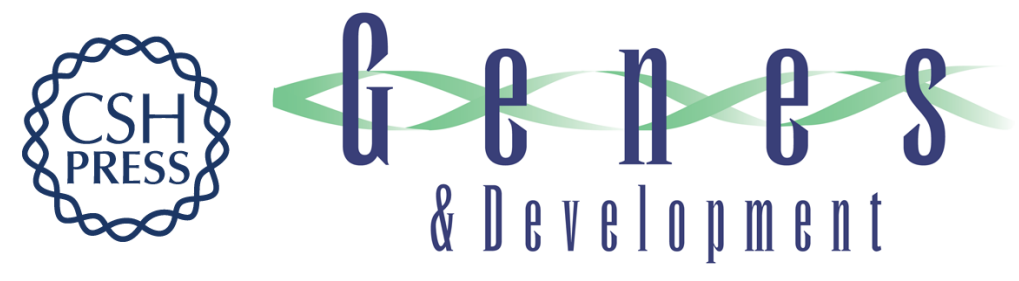

\section{Stress-induced cleavage of Myc promotes cancer cell survival}

Maralice Conacci-Sorrell, Celine Ngouenet, Sarah Anderson, et al.

Genes Dev. 2014, 28:

Access the most recent version at doi:10.1101/gad.231894.113

\section{Supplemental Material \\ http://genesdev.cshlp.org/content/suppl/2014/04/02/28.7.689.DC1}

References This article cites 78 articles, 36 of which can be accessed free at: http://genesdev.cshlp.org/content/28/7/689.full.html\#ref-list-1

Creative This article is distributed exclusively by Cold Spring Harbor Laboratory Press for the first Commons License six months after the full-issue publication date (see http://genesdev.cshlp.org/site/misc/terms.xhtml). After six months, it is available under a Creative Commons License (Attribution-NonCommercial 4.0 International), as described at http://creativecommons.org/licenses/by-nc/4.0/.

Email Alerting Receive free email alerts when new articles cite this article - sign up in the box at the top Service right corner of the article or click here.

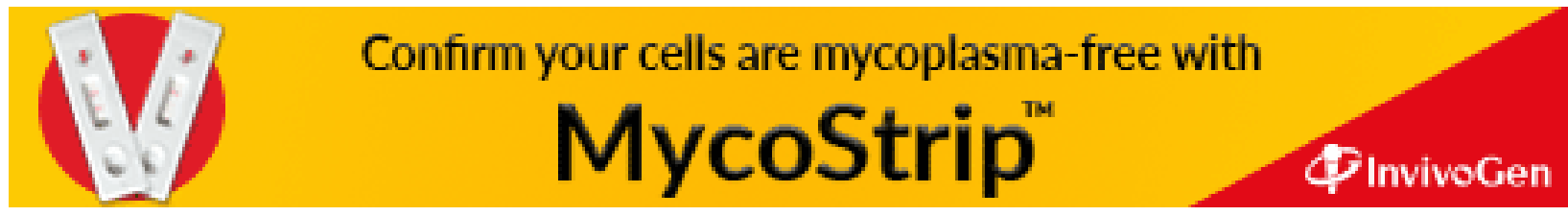

